\title{
The neuropsychology of consumer behavior and marketing
}

\author{
Steven D. Shaw | Richard P. Bagozzi
}

Stephen M. Ross School of Business, University of Michigan, Ann Arbor, MI, USA

\section{Correspondence}

Steven D. Shaw,

Stephen M. Ross School of Business, University of Michigan, Ann Arbor, MI, USA. Email: shawsd@umich.edu

\begin{abstract}
Insights and tools from neuroscience are of great value to marketers. Neuroscientific techniques allow consumer researchers to understand the fundamental neural underpinnings of psychological processes that drive consumer behavior, and elucidate the "black box" that is the consumer's mind. In the following review, we provide an overview of the fundamental tenets of consumer neuroscience, selectively outline key areas of marketing that consumer neuroscience has contributed to, compare and contrast neuroscientific tools and methods, and discuss future directions for neurophysiological work in marketing. In doing so, we illustrate the broad substantive landscape that neuroscience can add value to within marketing.
\end{abstract}

\section{KEYWORDS}

consumer behavior, consumer neuroscience, decision-making, decision neuroscience, genetic associations, marketing, neuroeconomics, neuromarketing, neurophysiology, neuroscience,

social neuroscience

\section{1 | INTRODUCTION}

Marketers are plagued with the reality that despite widespread use of self-assessment measures, such as surveys and questionnaires, consumers are unskilled at retrospective introspection (Nisbett \& Wilson, 1977). In search of more objective and reliable insights into consumer thought processes, the use of psychophysiological measures to study consumer behavior began with electrodermal responses in the 1920s (Bagozzi, 1991) and pupillary dilation in the 1960s, followed shortly after by eye-tracking and heart rate measures (Wang \& Minor, 2008). More recently, technological advances have led marketers to use electroencephalography (EEG) and functional magnetic resonance imaging (fMRI; see Table 1 for an overview of neuroscientific methods; Kenning, Plassmann, \& Ahlert, 2007). Such applications of neuroscientific techniques to study consumers' emotions and cognitive responses have spawned the field of consumer neuroscience. Consumer neuroscience, defined as applying "tools and theories from neuroscience to better understand decision making and related processes" (Plassmann, Venkatraman, Huettel, \& Yoon, 2015; p. 427), is an interdisciplinary academic subfield of marketing and neuroeconomics, at the intersection of neuroscience and consumer psychology, and overlaps with decision neuroscience. Consumer neuroscience is differentiated from neuromarketing in that the latter involves the practical implementation of neuroscientific knowledge (often derived by consumer neuroscience), primarily in industry, for company-specific marketing insights (Hubert $\&$ Kenning, 2008).

The use of neuroscientific techniques in marketing has generated considerable interest and excitement in recent years, evidenced by an increasing number of publications and review papers in the area (e.g., Kenning \& Plassmann, 2008; Plassmann, Ambler, Braeutigam, \& Kenning, 2007; Plassmann et al., 2015; Smidts et al., 2014; Solnais, Andreu-Perez, Sánchez-Fernández, \& Andréu-Abela, 2013; Yoon et al., 2012), as well as significant investments by industry leading marketing research and advertising agencies in neuroscience divisions (including Nielsen, Ipsos, and Millward Brown). For example, in 2015, The Journal of Marketing Research, one of the top academic journals in marketing, published a special issue on neuroscience and marketing (Camerer \& Yoon, 2015). In industry, one of the world's largest market research firms, Nielson, acquired Neurofocus, a leading neuromarketing firm, in 2011 (Hsu \& Yoon, 2015).

The primary reason for such heightened interest in neuroscience within marketing is the promise that neuroimaging techniques, and the data that they generate, may allow researchers to unravel the "black box" inside the mind of the consumer (Fugate, 2007; Lee, Broderick, $\&$ Chamberlain, 2007). Behavioral outcomes, as well as the consumer processes associated with those outcomes, are of great importance 


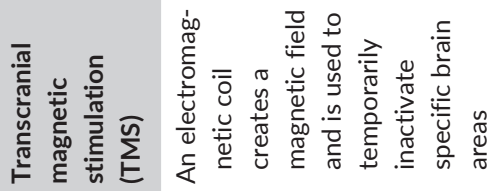

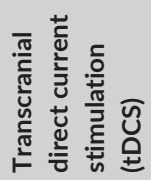

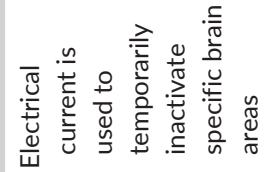

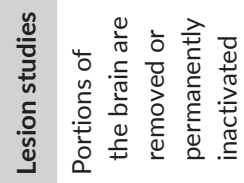

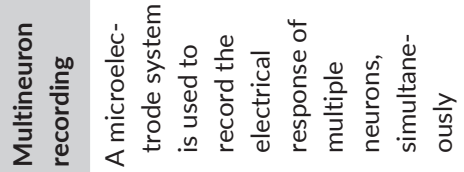

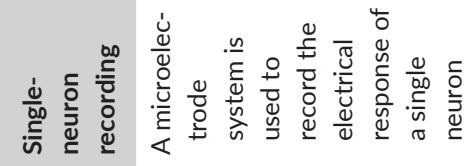

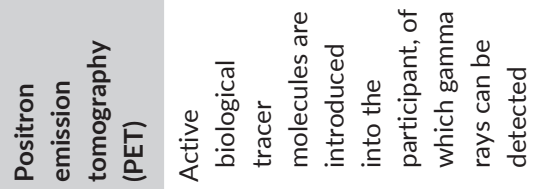

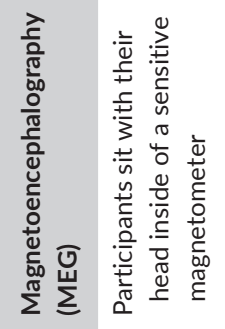

으 $\stackrel{\varangle}{z}$

오 $\stackrel{\varangle}{z}$

$\stackrel{\Perp}{\succ} \overleftarrow{z}$

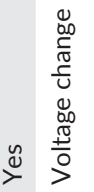

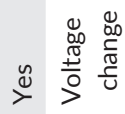

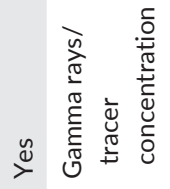

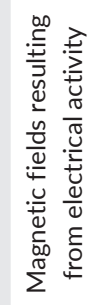

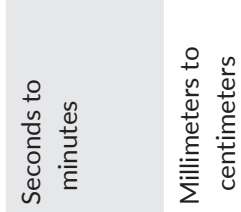

岂

능

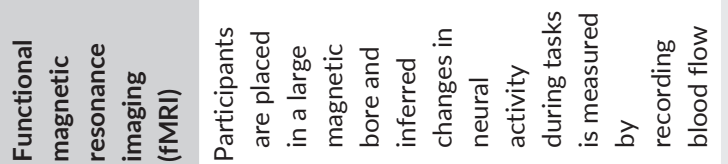

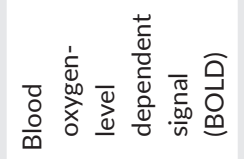

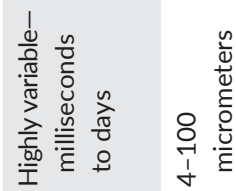

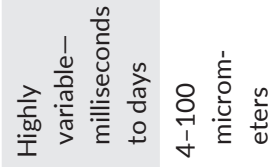
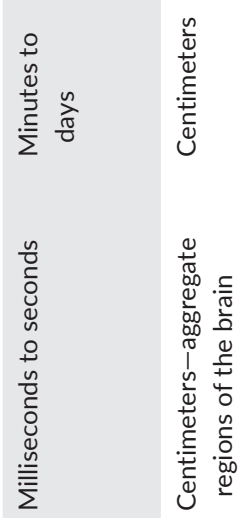

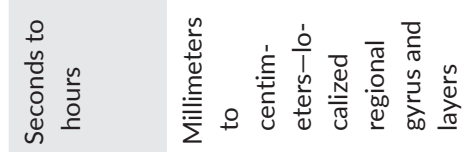

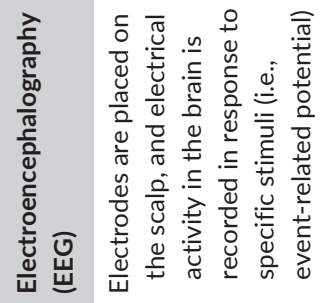

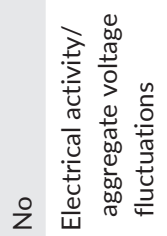

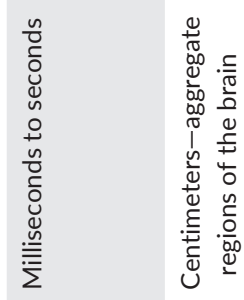

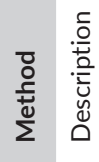

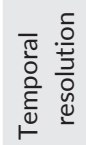




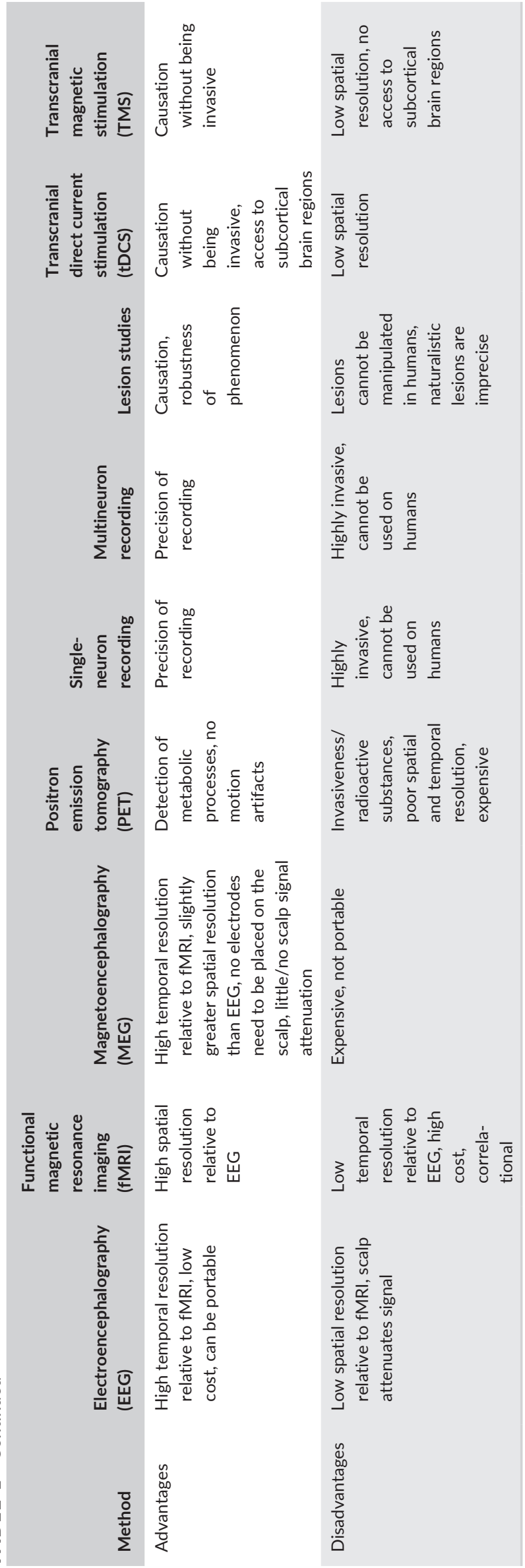

to marketers. However, similar behaviors within an individual, and between individuals, may be elicited as a result of highly different underlying psychological processes, many of which are not readily observable using traditional research methods (Adolphs, 2010; Sanfey, Rilling, Aronson, Nystrom, \& Cohen, 2003). Thus, neuroimaging techniques are attractive in marketing applications because they provide researchers and practitioners with seemingly objective physiological data, are potentially less susceptible to experimenter bias or demand effects, and can be more reliable than self-report data (Camerer, Loewenstein, \& Prelec, 2005).

The purpose of this article was to review the foundational tenets of consumer neuroscience, providing readers with a basic understanding of the neural basis of fundamental cognitive and affective processes, to provide a selective review of current research in consumer neuroscience, to summarize common neuroscientific tools and methods, and to discuss the future of neuroscience and marketing.

\section{2 | FOUNDATIONAL TENETS OF CONSUMER NEUROSCIENCE}

Human decision-making is carried out through a complex symphony of neuronal firing and functional circuitry. The neurobiological components underlying cognitive and affective processes rely on nonmutually exclusive functional neuroanatomy. For this reason, researchers use simplified abstractions of brain areas and neural circuits to organize scientific knowledge. Such abstractions represent the most essential biological components necessary for a given neural process and omit many details for brevity. Here, we consider four neural circuits commonly studied in consumer and decision neuroscience: (a) attention, (b) memory, (c) emotional processing, and (d) reward processing.

\section{1 | Attention}

At any given moment, our senses are bombarded with vastly more sensory information from environmental stimuli than can be effectively processed in the brain. With such a vast disparity between the amount of incoming information and our processing capacity, determining which information to process (or attend to) is critical for decisionmaking. Attentional mechanisms modulate the selective concentration of specific stimuli, or certain discrete aspects of stimuli, while de-emphasizing or ignoring other stimuli or distractors. Two primary modes of attention exist: bottom-up attention and top-down attention (Kastner \& Ungerleider, 2000). Whereas bottom-up attention is driven by environmental cues (e.g., a shocking noise or unexpected scent; Duncan \& Humphreys, 1989; Treisman \& Gelade, 1980), top-down attention is driven by an individual's internal goals and motivations (e.g., reading a book), external states, or expectations (Connor, Egeth, \& Yantis, 2004; Corbetta \& Shulman, 2002). Bottom-up attention is automatic, or unconsciously driven, and essential for first-impression judgments of stimuli. For example, when viewing marketing stimuli, initial eye movements are driven by bottom-up factors, such as color and brightness, and within the first $2.5 \mathrm{~s}$ consumers make an average 
of four eye movements (Huddleston, Behe, Minahan, \& Fernandez, 2015; Milosavljevic, Navalpakkam, Koch, \& Rangel, 2012).

In contrast, top-down attention is conscious, and information that is relevant to a consumer's goals or expectation is given attentional priority/emphasized (Wolfe \& Horowitz, 2004). Much research has been conducted examining the functional pathways involved in bottom-up and top-down attention. Key brain regions associated with bottom-up attention include the insula, anterior cingulate cortex, and dorsolateral prefrontal cortex (Felleman \& Van Essen, 1991; Ungerleider \& Haxby, 1994). Conversely, the key brain regions associated with top-down attention include the dorsolateral prefrontal cortex, inferior parietal sulcus, inferior frontal gyrus, middle temporal gyrus, posterior cingulate cortex, and precuneus (Cook \& Maunsell, 2002; Luck, Chelazzi, Hillyard, \& Desimone, 1997; Noudoost, Chang, Steinmetz, \& Moore, 2010).

The largest portion of incoming environmental information is visual, and, as a result, vision processing is dominant among the human senses (Kaas, 2008; Koch, 2004). Several regions in the prefrontal cortex are believed to be essential to both bottom-up and top-down attentional processes. In particular, although raw visual information is processed in the occipital lobe, connections to neurons in the prefrontal cortex appear to direct and focus visual attention (Armstrong, Fitzgerald, \& Moore, 2006). Two cortical routes are involved in visual processing: the dorsal visual pathway and the ventral visual pathway. The dorsal visual pathway runs from the primary visual cortex V1 to the dorsolateral prefrontal cortex, routing through the posterior parietal cortex, and is primarily involved in the spatial deployment of attention. Conversely, the ventral visual pathway runs from the primary visual cortex $\mathrm{V} 1$ to the ventrolateral prefrontal cortex, routing through the inferotemporal cortex, and is primarily involved in object recognition. Given attentional biases toward visual processing, stimuli that are visually salient (e.g., brighter, more colorful) are often attended to more rapidly or for a longer amount of time than those that are not visually salient (Milosavljevic et al., 2012; van Zoest, Donk, \& Theeuwes, 2004).

\section{2 | Memory}

In order for past information to influence future decisions, it must be encoded, consolidated, and retrieved. Defined as "any physical change that carries information about the historical past" (Redish \& Mizumori, 2015), memory is the brain's mechanism for the retention and retrieval of information. Such retention of information is essential for learning and determining future actions. For this reason, memory and decision-making are tightly intertwined. Multiple memory systems exist within the brain (Eichenbaum, 1994; McDonald \& White, 1993; Squire, Knowlton, \& Musen, 1993). Categorically, there are three different types of memory: sensory memory (Sperling, 1963), short-term or working memory (Baddeley, 2017; Miller, 1956), and long-term memory (Bliss \& Collingridge, 1993; McGaugh, 2000). Within longterm memory, implicit or procedural memories, which are processed unconsciously, are associated with activation in the striatum and cerebellum (Doyon et al., 1998; Packard, Cahill, \& McGaugh, 1994).
Alternatively, explicit or declarative long-term memories, which are processed consciously, can be episodic (memory for events or experiences) or semantic (memory for facts or concepts). Broadly, declarative memory traces are largely associated with activation in the hippocampus and surrounding neocortex, such as the medial temporal lobe (Eichenbaum, 2000). Memory for aversive or fearful negative events is associated with activation in the amygdala (Murray, 2007).

Memory consolidation, which is essential for the formation of long-term memories, occurs via long-term potentiation, or the neural strengthening of patterned synapse activation (Lynch, 2004). Evidence suggests that the amygdala plays an important modulating role in memory consolidation, functioning to determine the strength and significance of memory traces, whereas the hippocampus acts as the primary locus of memory processing and consolidation (McGaugh, 2000). Given that the amygdala is heavily involved in both emotional processing (discussed below) and the modulation of memory formation, it is not surprising that emotionally arousing experiences are better remembered than nonemotionally arousing experiences (Christianson, 1992). The amygdala can modulate memory formation strength by signaling for the release of hormones along the hypothalamic-pituitary-adrenal axis (Smith \& Vale, 2006). Greater strength of remembrance for emotional experiences is regulated by the release of the adrenal stress hormones, such as epinephrine and cortisol (Gold \& Van Buskirk, 1975). For example, amygdala inactivation during fear conditioning prevents learning of the fearful stimuli from taking place (Muller, Corodimas, Fridel, \& LeDoux, 1997).

\subsection{Emotional processing}

Subjective feelings, such as happiness, sadness, fear, anger, surprise, and disgust, play an important role in decision-making and postdecision appraisal (Ekman, 1992, 1999). At the neural level, two theoretical approaches for understanding emotion exist: the locationist approach, which hypothesizes that discrete emotional categories are tied to specific brain areas, and the psychological constructionist approach, which hypothesizes that emotional processes are constructed from interactions between general neural networks that are not specific to emotion categories. Although significant meta-analytical evidence supporting the psychological constructionist approach exists (see Lindquist, Wager, Kober, Bliss-Moreau, \& Barrett, 2012), the vast majority of past research on emotional processing within the brain relies on the locationist approach. Neural activation results from studies using a locationist approach can provide the foundation for the interrelated neural networks of noncategorical emotional responses hypothesized by constructionist approaches. For a psychological constructionist summary of brain networks consistently activated during specific mental states and emotional methodological manipulations, see Table 3 of Lindquist et al. (2012).

According to the locationist approach, the primary neural correlates of emotion are the medial prefrontal cortex, amygdala, along with the thalamus and hypothalamus, the insular cortex, the orbitofrontal cortex, nucleus accumbens, and the anterior cingulate cortex. Of central importance to emotional processing, and most well 
researched, is the amygdala, which primarily processes negative emotions, fear, unknown stimuli, and inequality (e.g., LeDoux, 2000, 2015; Rilling \& Sanfey, 2011). Previous research has also linked insular cortex activation with the perception and/or expectation of risk (Preuschoff, Quartz, \& Bossaerts, 2008), as well as anger over unfair situations (Sanfey et al., 2003), and disgust (Jabbi, Bastiaansen, \& Keysers, 2008; Wicker et al., 2003). The orbitofrontal cortex appears to play a role in anger (Murphy, Nimmo-Smith, \& Lawrence, 2003; Vytal \& Hamann, 2010), and feelings of regret after decision outcomes that differ from one's expectations (Coricelli et al., 2005). The nucleus accumbens, in concert with other reward-related brain regions, also plays a role in emotional processing, largely in conjunction with the neurotransmitter dopamine, relating to "motivational processes including behavioral activation, exertion of effort, approach behavior, and sustained task engagement" function (Salamone \& Correa, 2012, p. 470). The anterior cingulate cortex has been primarily associated with sadness (Murphy et al., 2003; Phan, Wager, Taylor, \& Liberzon, 2002), but is believed to be involved in the processing of a variety of other neural emotional responses and the integration of emotional responses into the decisionmaking process (Bush, Luu, \& Posner, 2000).

\section{4 | Reward processing}

Cost-benefit analysis is necessary for determining the utility of option alternatives. The dopaminergic circuit, referred to previously, which includes brain areas involved in the neurotransmitter dopamine's synthesis and reception, is broadly associated with reward processing. Key elements of the dopaminergic reward circuit are the ventral tegmental area, the amygdala, striatum (putamen, caudate nucleus, and nucleus accumbens), ventral pallidum, insular cortex, and prefrontal cortex (particularly the orbitofrontal cortex; Arias-Carrión, Stamelou, Murillo-Rodríguez, Menéndez-González, \& Pöppel, 2010; see also Kringelbach \& Berridge, 2012).

The reward circuit is activated in response to subjectively attractive desirable resources and experiences, such as food (Berridge, 1996), money (Knutson, Adams, Fong, Walker, \& Hommer, 2001), sex (Pfaus, 2009), and drugs (Wise \& Rompre, 1989). More specifically, the ventral tegmental area is responsible for the synthesis and transmission of dopamine to other areas of the dopaminergic circuit (Fields, Hjelmstad, Margolis, \& Nicola, 2007). The striatum is also crucially implicated in forming evaluative expectations (Knutson \& Wimmer, 2007) and social reward processing (Fliessbach et al., 2007).

Reward can be separated into two dissociable psychological components: wanting (or incentive salience) and liking (or hedonic impact; Berridge, Robinson, \& Aldridge, 2009; Pool, Sennwald, Delplanque, Brosch, \& Sander, 2016). Wanting promotes the approach and consumption of rewards (rather than withdrawal)-wanting has a motivational component, is incentive salient, and neurobiologically distinct from liking.

The wanting system is a network of brain processes that govern motivation and is expressed as the desire for rewards. The wanting system gives "a visceral oomph to mental desires" (Berridge, 2009, p. 378). Evidence for the neural basis of wanting has primarily been found in the subcortical brain circuits, with the mesolimbic dopamine system being of particular importance (Berridge et al., 2009). Namely, the neural wanting system consists of the ventral tegmental area, nucleus accumbens, ventral pallidum, amygdala, anterior cingulate cortex, orbitofrontal cortex, and insular cortex. Dopamine, produced in the ventral tegmental area, spreads throughout the wanting system to influence desires for specific rewards and effort expended thereof. On the other hand, liking is the core process of hedonic pleasure-it is foundational, evolutionarily ancestral, and unconscious or implicit (Winkielman, Berridge, \& Wilbarger, 2005).

The liking system regulates pleasure responses and is composed of a small number of "hedonic hot spots" in the brain. Hedonic responses occur in the form of "sensory pleasures as well as many higher types of pleasure (e.g., cognitive, social, aesthetic, and moral)" (Berridge \& Kringelbach, 2015, p. 646). Whereas dopamine is a pervasive mechanism for reward processing in the wanting system, the liking system has a small number of regions where opioids and endocannabinoids intensify sensations of pleasure (e.g., Kringelbach \& Berridge, 2012; Salamone \& Correa, 2012). The nucleus accumbens and ventral pallidum interact with each other in this regard and send information to the orbitofrontal cortex, where higher-order cognitive processing occurs. Within the limbic system, opioid, endocannabinoid, and GABA systems are particularly important for liking reactions. In nonhuman animals, observations of positive affective facial expressions have been used to map specific hedonic hot spots, including opioid enhancement of liking in the rostrodorsal quadrant of the medial shell of the nucleus accumbens (Peciña \& Berridge, 2005) and ventral pallidum (Smith \& Berridge, 2005), and endocannabinoid enhancement of liking in the nucleus accumbens (Mahler, Smith, \& Berridge, 2007). Thus, although distinct, the wanting and liking systems overlap in terms of brain regions; both systems combine to produce subjective feelings of pleasure.

The wanting and liking systems have obvious implications for decision-making by consumers and managers and also relate to satisfaction. We will provide an example shortly, during the discussion of genetic factors, wherein gene variants, psychological phenotypes, and stress are shown to combine to influence wanting and liking, which in turn drive goal striving and satisfaction.

\section{3 | A REVIEW OF CONSUMER NEUROSCIENCE}

The goal of consumer neuroscience is to apply neuroscientific theory and methods to better understand consumer psychology. In doing so, behavioral theories, models, and methods from consumer psychology are combined with those from neuroscience, in an attempt to appreciate the biological contribution of consumer behavior. In this section, we selectively review literature from three key research areas that consumer neuroscience has added significant value to: (a) advertising and branding, (b) consumer preference and choice, and (c) price, product, promotion, and place (i.e., the marketing mix). 


\section{1 | Advertising and branding}

Primarily using fMRI, a number of initial studies investigating brand favorability, brand associations, brand recall, and brand loyalty have been conducted (Plassmann, Ramsøy, \& Milosavljevic, 2012). Research on brand favorability is intended to develop a better understanding of the neural mechanisms that are responsible for brand preference. Deppe, Schwindt, Kugal, Plassmann, and Kenning (2005) show that when consumers make decisions in which a choice set contains the consumer's favorite brand (as compared to a choice set without the consumer's favorite brand), there is increased activation in the ventromedial prefrontal cortex. Additionally, such choice sets containing a consumer's favorite brand resulted in reduced activation of the dorsolateral prefrontal cortex, inferior frontal gyrus, and cuneus/precuneus (visual cortex). These neural correlates of brand favorability appear to be modulated by the anterior cingulate cortex, which has been shown to predict the degree of bias an individual affords a brand on judgments of product attractiveness and credibility (Deppe et al., 2005, 2007).

Evidence for similar biasing of choice by brand preferences comes from a lesion study by Koenigs and Tranel (2008), which demonstrated that significant Coke versus Pepsi brand preference reversals between blind and open trials were not observed in patients with ventromedial prefrontal cortex lesions, but were observed in healthy consumers. That is, patients with ventromedial prefrontal cortex lesions had consistent preferences, regardless of whether the brand was present or not, whereas the preferences of healthy consumers were biased when brand information was present. Additionally, in uncertain decisions, brand preference amplifies the intensity of ventromedial prefrontal cortex activation (Plassmann, O'Doherty, Shiv, \& Rangel, 2008). The striatum has also been implicated in the predictive value of brand favorableness. Schaefer and Rotte $(2007 a, b)$ found that activity in the ventral striatum positively correlated with degree of sports and luxury characteristics of a brand (e.g., imagining driving in a BMW vs. an unbranded car), but negatively correlated with rational choice attributions of the brands.

Brand associations are learned attributes or values that a brand elicits in a consumer's mind. Initial work by Erk, Spitzer, Wunderlich, Galley, and Walter (2002), and later corroborated by Schaefer and Rotte (2007a), showed that brands that are known to signal high social status, through wealth and social dominance, are associated with the brain's reward circuit, specifically the striatum, ventromedial prefrontal cortex, medial orbitofrontal cortex, and anterior cingulate cortex. Additionally, car brands signaling low status have been associated with activation in the superior frontal gyrus and anterior cingulate cortex (Schaefer \& Rotte, 2007b). Thus, experiencing brands that signal high social status seems to be rewarding to the consumer, on a neural level. Similarly, some evidence suggests that brands can alter actual consumption experience (i.e., brand information changes the neural response when consuming the product). For instance, in seminal work by McClure et al. (2004), consumers who knew they were drinking Coke, versus those who knew they were drinking Pepsi (or those who did not know what brand they were drinking), displayed neural activation changes in the memory circuit (i.e., hippocampus, dorsolateral prefrontal cortex, and superior frontal gyrus). That is, behavioral preferences for Coke were only partly determined by sensory information, and activation in the memory circuit as a result of brand information biased such preferences.

One of the most well-studied types of brand associations is the so-called brand personality, which posits that brands have personality characteristics, similar to humans, and consumers are able to form relationships with brands in an analogous manner to those formed with people (Aaker, 1997; Aaker \& Fournier, 1995). Neuroscientific methods can be used to test and validate behavioral measures and claims. In the case of brand personalities, a study by Yoon, Gutchess, Feinberg, and Polk (2006) showed that the neural systems involved in personality judgments of humans are not the same as brand personality judgments. More specifically, person judgments were associated with activation in the medial prefrontal cortex regions, while judgments of brands were associated with activation in the left inferior prefrontal cortex, which is typically involved with object recognition. Such results illustrate how neuroscientific techniques can illuminate invalid assumptions that can underlie behavioral consumer research, including widely popular ideas and constructs (Azoulay \& Kapferer, 2003).

Brand recall, familiarity, and memory for a brand have implications for top-of-mind awareness and brand perceptions. Familiar brands, versus unfamiliar brands, are associated with activation in the middle frontal gyrus (Schaefer, Berens, Heinze, \& Rotte, 2006). Familiar, favorable brands that are well established in consumer's mind (socalled strong brands) elicit different neural responses than familiar but unfavorable or unestablished brands (so-called weak brands). In comparison with weak brands, strong brands engage the dorsolateral prefrontal cortex, while weak brands engage the insula more heavily (Esch et al., 2012). Similar to brand associations, expert endorsements have been shown to improve brand recall and are associated with activation in the memory circuit (Klucharev, Smidts, \& Fernández, 2008). Thus, relationships between consumers and brands can be observed, validated, and quantified at the psychophysiological level.

Finally, initial work on the neural correlates of consumer loyalty has validated the importance of loyalty in the marketing environment. Using point of sale scanner data and inviting loyalty card holders of different retail stores into a neuroimaging laboratory, Plassmann, Kenning, and Ahlert (2007) showed that, when choosing between purchasing identical clothing items at different retail stores, consumers who are loyal to a store show more activation in the striatum as compared to consumers who are less loyal. That is, neural activation patterns showed that customer loyalty results in neural activation patterns consistent with the notion that consumers form affective bonds with the store or brand and illustrates the importance of the emotional component of consumer loyalty.

\subsection{Consumer preference and choice}

Why do consumers choose the products that they end up purchasing? Preference formation and choice have been the subject of much research, exemplified by choice theories across fields of marketing, economics, psychology, and political science. However, 
behavioral data can only provide a limited amount of insight into the processes underlying consumer preference and choice. As a complement, neuropsychological data provide rich insight into consumer thought processes, and thus, examining the neurobiological mechanisms underlying preference and choice processes is of great interest to researchers.

Much of the initial psychophysiological work on consumer preference and choice has focused at the developmental level (i.e., how the individual, and their brain, is shaped by sociocultural factors during childhood and adolescence). Cultural and social influences during psychological development play a key role in preference formation. For example, children as young as 3 years old can recognize and represent brand logos (McAlister \& Cornwell, 2010). Some important developmental milestones, such as the representation and recognition of visual stimuli, occur during critical periods of development during adolescence and early childhood (Somerville \& Casey, 2010). Critical and sensitive periods are times during development at which certain developmental processes, such as specific cognitive skills or abilities, take place. Previous research shows that the formation of certain preferences occurs during critical periods. Holbrook and Schindler (1989) provide evidence for the critical period account of preference formation for musical taste. By correlating musical preferences and participants age at the time selected songs were popular, the researchers show strong evidence that musical preference formation occurs in the early 20s. Understanding preference formation is essential, because preferences ultimately influence choice.

Choice is the primary outcome of decision theories and therefore is important to marketers. Many factors influence choice, including environmental factors at the time of the decision, such as location the of a product on the shelf in a store (Durgin, Doyle, \& Egan, 2008; Efron \& Yund, 1996) or the number of products being chosen from (Scheibehenne, Greifeneder, \& Todd, 2010), and biological factors, such as the ability to remember which product one bought previously or misremembering crucial information about product attributes (Skurnik, Yoon, Park, \& Schwarz, 2005).

A common challenge faced by modern consumers, when presented with choice decisions among product alternatives, is the overwhelming availability of many alternatives. Given constraints on memory and attention, leading choice theories postulate that consumers first filter the alternatives into a small set prior to making a final decision. The smaller set of alternatives that remains after filtering is called the consideration set. Models of consumer choice that include a consideration set stage are significantly better at predicting choice than standard models using only choice data (Shocker, Ben-Akiva, Boccara, \& Nedungadi, 1991). Evidence suggests that consideration sets are often in the range of 3 to 6 items (Hauser \& Wernerfelt, 1990). Cognitive resources, such as deliberation, memory, and attention, are only devoted to items within the consideration set. At the neural level, consideration set size seems to be related to activity in the striatum, dorsal anterior cingulate cortex, and insula (Kim, Shin, \& Han, 2014)

\section{3 | Price, product, promotion, and place}

The marketing mix, also known as the four P's of marketing, is a foundational categorical concept in marketing and represents four essential aspects of marketing campaigns. Consumer neuroscience has much to contribute to understanding how each aspect of the marketing mix can be optimized at the consumer level. Modifiable aspects of the marketing mix can dramatically influence consumer perceptions and ultimately the success of a marketing campaign. For example, it is now clear that modifiable marketing mix variables, such as price, influence experienced utility of products above and beyond intrinsic aspects of the product (e.g., taste).

Price differences have been shown to markedly impact product perceptions. A seminal study demonstrating the malleability of price perceptions showed that not only does price influence perceived quality, but neural activation differs as a result of the expectancies created by given price points. Plassmann et al. (2008) conducted a study showing that consumers who tasted the same wine on multiple occasions, but were made to believe the samples had different prices (i.e., they tasted the same wine but believed it was cheap or expensive, between tastings), actually experienced the wine samples differently; beliefs about quality, based on price, altered activation in the medial orbitofrontal cortex when tasting wine. Additionally, excessive prices have been shown to activate the insula and deactivate the mesial prefrontal cortex (Knutson, Rick, Wimmer, \& Prelec, 2007).

Another price-related concept that evidence from consumer neuroscience has contributed to is willingness to pay. In a study investigating the neural correlates of willingness to pay, or the maximum price that an individual would be willing to pay for a given product, Plassmann, O'Doherty, and Rangel (2007) scanned hungry participants and asked them how much they would pay for a variety of foods. Results implicated activation in the medial orbitofrontal cortex with willingness to pay computation, and the dorsolateral prefrontal cortex with decision execution. The order with which price information is presented has also been studied at the neural level. Karmarkar, Shiv, and Knutson (2015) show that when pricing information is revealed before consumers see a product, there is altered activity in the medial prefrontal cortex, and subsequently, consumers value the product differently. Neural activation results like these are beginning to shed light on how our brain computes and represents value in everyday choices.

Intangible features of a product, such as product design, have implications for the success of the product (Bloch, 1995). Evidence from fMRI research shows that visual product attractiveness is associated with activation in the ventral striatum, which houses the nucleus accumbens (Erk et al., 2002). Such findings could be used to optimize intangible product qualities. In addition to product attractiveness, overall individual product preference is correlated with activation in the nucleus accumbens (Knutson et al., 2007). Thus, neural measures can detect biological responses to intangible product preferences, which cannot be observed easily or accurately using traditional marketing measures.

Research on promotion within consumer neuroscience has likely received the least amount of attention, but is beginning to develop 
and gain importance. One area that has been studied is the effect of celebrity and/or expert endorsements on promotional material. Stallen et al. (2010) suggest that celebrity endorsement pairings are effective because they increase positive affect and spontaneously elicit the retrieval of explicit memories related to the celebrity, indicated by increased activation in the medial orbitofrontal cortex when viewing celebrity endorsers, versus viewing equally attractive nonfamous endorsers. Similarly, promotion using "expert power," or the persuasive effect of communicators with expertise, has been shown to have extensive memory and attitudinal effects on the product. Klucharev et al. (2008) show that expert content is associated with left-lateralized prefrontal and temporal brain activity, related to semantic elaboration, hippocampus and parahippocampal gyrus activity, related to memory formation, and caudate nucleus activity, related to trust, reward, and learning.

Despite the current lack of neurophysiological research on promotion, one of the most promising areas of consumer neuroscience, neuroforecasting, is beginning to gain traction. Neuroforecasting uses insights from the neural activity of a small group of subjects $(\sim 30)$, scanned using $\mathrm{fMRI}$, to predict generalizable, aggregate, marketlevel choice forecasts. Initial forecasting studies have illustrated the feasibility of neuroforecasting. In these studies, neural responses to early market conditions are used to create a predictive model of mature market outcomes, and this neural model is then tested against self-report models using real-world market data once the market has matured (i.e., after a sufficient passage of time). For example, Falk, Berkman, and Lieberman (2012) used medial prefrontal cortex activity to forecast advertisement call volume, and Berns and Moore (2012) used nucleus accumbens activation to forecast aggregate song downloads. Additionally, Genevsky, Yoon, and Knutson (2017) were able to use neural data to predict both individual- and market-level choices for crowdfunding (i.e., raising funds for a project, cause, or product through small contributions from a large number of people). The authors found that activity in the nucleus accumbens and medial prefrontal cortex was predictive of individual-level choices, whereas only activity in the nucleus accumbens was predictive of market-level internet funding several weeks later. Importantly, in the crowdfunding domain, behavioral measures were not predictive of market-level outcomes, illustrating the unique value of neural data on forecasting.

The placement of products, whether it be on a shelf or online, is another element of the marketing mix that influences the success of marketing efforts. The location of products in displays matters-some locations can attract more attention than others (Pieters \& Warlop, 1999). Eye-tracking studies have shown that automatic visual attentional biases exist. For example, among products on a shelf, there is a visual attentional bias toward the upper visual field (Durgin et al., 2008) and right visual field (Efron \& Yund, 1996). That is, products place on the upper shelves and to the right, within a given category, received longer eye fixations (i.e., were paid more attention to and subsequently chosen more frequently). In online settings, there is a strong visual bias toward information presented in the center of the computer screen (Tatler, 2007). Among similar items presented in an online setting, products placed in the center of the screen, versus products placed elsewhere, are nearly $60 \%$ more likely to be selected (Reutskaja, Nagel, Camerer, \& Rangel, 2011).

\section{4 | NEUROSCIENTIFIC METHODS AND TOOLS}

Neuroscientists use a broad array of methods to study the brain, behavior, and their intersection. Importantly, these methods differ in the spatiotemporal resolution at which they measure brain activity, invasiveness, and type of brain activity that they measure (e.g., correlational versus causational observations). In human studies, the most commonly used methods for recording brain activity are electroencephalography (EEG) and functional magnetic resonance imaging (fMRI). These techniques are popular because they can be administered to healthy adult populations and are noninvasive. Whereas EEG has relatively high temporal resolution and is low cost, making it popular among neuromarketers, its spatial resolution is relatively low (on the order of centimeters), and depth of processing shallow, making differentiation between certain neural regions and pathways difficult to ascertain (see Refai \& Bagozzi, in press, for a review of the use of EEG in marketing). Conversely, $\mathrm{fMRI}$ is used among consumer neuroscientists and clinicians for scientific research and patient diagnosis, respectively, due to its higher spatial resolution (on the order of millimeters) and comprehensive depth of processing. Although fMRI has much higher costs than EEG, in terms of scanner maintenance, operations, and participant incentives, and lower temporal resolution (on the order of seconds), the spatial resolution allows one to discern between cognitive pathways.

Other neuroscientific techniques used to study the brain and behavior include: magnetoencephalography (MEG), positron emission tomography (PET), single and multineuron recording, lesion studies, transcranial direct current stimulation (tDCS), and transcranial magnetic stimulation (TMS). Of these, PET, single and multineuron recording, and lesion studies are all invasive, which limits their usefulness to applied behavioral researchers, because their application on humans is difficult and potentially unethical. These techniques are often restricted to nonhuman animal research. However, tDCS and TMS are noninvasive and could prove highly useful to marketers in the future as they may serve as a means to establish the causality of previous correlational findings (i.e., corroborate finding from EEG or fMRI) and/ or establish effect sizes. Table 1 provides an overview of neuroscientific methods, as well as their strengths and weaknesses for marketers.

\section{5 | FUTURE DIRECTIONS FOR NEUROSCIENCE IN MARKETING}

As the biological influences of consumer behavior become better understood and accepted, there is a necessity for integrative approaches across neuroscience and marketing. Additionally, technologies available for noninvasively measuring biological features are becoming less expensive and more readily available, opening many 
neurophysiological avenues to marketers for future research. In the succeeding sections, we discuss five key topics that we believe are essential for the future of neuroscience in marketing: (a) a need for fundamental integrative approaches to neuroscience and suggestions for critical areas of consideration, (b) the examination of genetic influences on consumer behavior, (c) incorporating naturalistic-like social consumption contexts into consumer neuroscience research designs, (d) consciousness, and (e) addressing the current limitations/common caveats of the field.

\section{1 | Need for fundamental integrative approaches to neuroscience}

Much neuroscience research to date in marketing, and consumer behavior, has been fragmented by examining narrow psychological processes (e.g., attention, memory, or emotional reactions). A need exists for studying basic, integrative psychological processes that address fundamental aspects of decision-making and involve multiple brain regions in a holistic way. Three basic integrative processes deserve greater scrutiny: theory of mind, empathy (mirror neurons), and behavior combining theory of mind and empathy.

\subsection{1 | Theory of mind}

Theory of mind concerns mentalizing in communication contexts and refers to how people infer the beliefs, thoughts, feelings, desires, traits, and decisions and intentions of other people (e.g., Frith \& Frith, 2008). Research in autism and other neurodevelopmental disorders has implicated the medial prefrontal cortex, temporal poles, temporal parietal junction, and precuneus regions of the brain in theory of mind processes, among other regions (e.g., Frith \& Frith, 2006; Lieberman, 2010). Essential psychological processes involved in theory of mind include taking the perspective of others, inferring what others are thinking, attributing causes or reasons for one's own behavior or the behavior of others, and aspects of moral decision-making.

One way that theory of mind has been studied in marketing is by manipulating the perception of interpersonal relations between people while in the $\mathrm{fMRI}$, and comparing to a control group in which stimuli had no interpersonal content, to see whether the brain regions associated with theory of mind are activated. The intensity of theory of mind neural activation has been shown to relate to self-reports of theory of mind, thereby relating objective, third-person evidence to first-person experiences of theory of mind processes (Dietvorst et al., 2009). Additionally, Dietvorst et al. (2009) illustrate how fMRI can be used in scale construction and validation.

Theory of mind processes undergird many phenomena in marketing. People watching interpersonal dialogue in advertisements, face-to-face exchanges by consumers and salespeople, everyday decision-making by individuals taking into account the needs and expectations of others, and group decision-making in family buying or organizational buying centers all involve strong, pervasive theory of mind processes. To the extent that marketers wish to understand and influence buying behavior, study of theory of mind processes can provide basic insights into decision-making, preference formation, choice, and patterns of behavior.

\subsection{2 | Empathy (mirror neurons)}

Empathy is not an emotion, but rather a compound psychological trait or state composed of empathetic concern (an affective reaction), taking the perspective of others (a largely cognitive theory of mind process), and self-other differentiation (a process related to identity and psychological distress, e.g., Decety \& Lamm, 2006; Walter, 2012). Empathy is a fundamental human mental process that is embedded in many levels of consumption. As such, neuroscience methods and tools are valuable for studying empathy. Empathy occurs when consumers engage in purchases of gifts, when they interact with other consumers in joint decision-making, when they engage in transactions with salespersons, when they learn about the abuse of animals, the plight of people in poverty, or experience natural disasters through advertising appeals, and many other everyday situations. Indeed, early economic thought by David Hume and Adam Smith stressed the role of empathy in business (they used the word, sympathy, because empathy had not yet entered the English lexicon).

Empathy is a foundation of many marketing concepts and informs strategic management decisions. Beyond a phenomenon for study in its own right, in consumption and marketing empathy has been shown to directly regulate the influence of perceptions of corporate (ir)responsibility on emotional reactions toward companies and indirectly on support for companies (e.g., Xie, Bagozzi, \& Grønhaug, 2015). Furthermore, utilizing perspectives and tools from neuroscience can deepen our understanding of how empathy functions as a main effect, mediator, and moderator in everyday consumption and managerial decisions. The emotional resonance aspects of empathy, such as those reflected in feelings of compassion for the suffering of others and empathetic concern and kindness toward others, have been found to be associated with regions of the brain identified as the mirror neuron system (e.g., Gallese, 2003; lacoboni, 2009). Among other regions, the insula, inferior frontal gyrus (pars opercularis), temporal parietal junction, superior temporal sulcus, and amygdala have been implicated in mirror neuron activation (Dapretto et al., 2006; Decety \& Lamm, 2006; van der Gaag, Minderaa, \& Keysers, 2007).

Mirror neuron system activation has been studied, using fMRI, by exposing people to video clips of positive and negative facial emotions, with neutral faces and moving geometric objects as controls. In one study, seeing facial expressions of emotions was found to produce activation of such mirror neuron components as the supplemental motor area, pre- and postcentral gyrus, and pars opercularis, as well as inferior and superior parietal lobule (Bagozzi et al., 2012). Importantly, intensity of activation of each of these regions was positively correlated in salespeople with customer orientation and uncorrelated with sales orientation (both first-person self-reports; see discussion of consciousness below). Customer orientation is the strategic or policy inclination to identify customer needs and adjust one's product or service and selling appeals to meet those needs. It is thus rooted in empathy. By contrast, a sales orientation is a one-sided or selfish policy 
to try to convince customers to buy one's product irrespective of customer needs (i.e., even if the customer might not need the product). A customer orientation is based more on mutuality and engenders cooperation and trust to work together to satisfy joint needs, whereas a sales orientation is based mostly on self-interest of the seller and often uses deception and manipulation to achieve seller ends at the expense of customers.

\subsection{3 | Integrating theory of mind and empathy in consumer behavior}

Many actions by consumers and managers involve a number of mental processes organized in complex ways. As an example, one study investigated the boundary conditions of sales account managers' self-interests in business relationships by studying the role of Machiavellianism in decision-making (Bagozzi et al., 2013). Machiavellianism is a kind of social conduct in which a person manipulates others for self-gain, and is conceptually similar to psychopathy and sociopathy. By studying managers in terms of theory of mind (i.e., taking the perspective of others) and empathy (i.e., resonating with the feelings of others with whom one interacts), it is possible to see how neural processes underpin Machiavellian behavior.

Previous self-report research on the relationship between theory of mind and Machiavellianism has been inconclusive, with studies showing both null and positive relationships (e.g., Paal \& Bereczkei, 2007; Repacholi \& Slaughter, 2003; Stellwagen \& Kerig, 2013). Neural evidence, however, can be used to help resolve previous inconsistencies in the literature, and illustrate how theory of mind and empathetic processes differentially influence Machiavellianism. Bagozzi et al. (2013) show that individuals who display more, versus less, Machiavellianism have less activation in the temporo-parietal junctions, medial prefrontal cortex, and precuneus. These are classic areas of the brain coinciding with autism and related to lower theory of mind capabilities. Hence, in comparison with non-Machiavellians, Machiavellians can be thought to be hindered in their abilities to infer the thoughts, beliefs, feelings, and other psychological states and traits of persons with whom they interact and observe. In other words, the basis for taking the perspective of others is weakened in Machiavellians compared to non-Machiavellians.

Additionally, Bagozzi et al. (2013) show that individuals who display more Machiavellianism display greater activation in the insula and pars opercularis. Interestingly, these areas of the brain are part of the mirror neuron system. Thus, when compared to non-Machiavellians, Machiavellians reveal greater emotional resonance (i.e., experience of others emotional states) to other persons with whom they might interact and observe, as illustrated by greater activation of mirror neuron systems. It should be noted that this result is likely to apply to automatic emotional reactions and not necessarily conscious empathetic responses. Activation of the precuneus was also negatively related to Machiavellianism. These neural associations further support the distinct and diverging results regarding Machiavellianism, providing novel insight into the cognitive processes underlying Machiavellianism: positive associations with emotional resonance and negative associations with cognitive theory of mind processes. Previous psychological research based on self-reports of perspective taking and empathetic concern has consistently maintained that both processes go together in characterizing Machiavellians (i.e., in cases in which associations between Machiavellianism, theory of mind, and empathy are observed, the relationship has been positive). However, using neuroscientific methods, the research described here shows that these two defining qualities, theory of mind and empathy, can in fact be related in opposite ways in Machiavellians. Thus, these findings provide an example of how integrative neural results go some distance in resolving controversies and inconsistencies in the psychological and organization behavior literature (see Bagozzi et al., 2013).

Theory of mind and empathy are two comprehensive, fundamental mental processes. Although complex and difficult to investigate, these processes can be usefully studied using neuroscientific techniques. In such complex, yet fascinating areas as theory of mind and empathy, opportunity exists for gaining deeper knowledge about consumer behavior and decision-making through the use of integrative hypotheses and neuroscientific techniques. Such projects cannot be easily or effectively approached by traditional experimental and survey methods relying on self-reported responses alone.

\subsection{Genetic influences on neural activity and behavior}

The human genome project, which sequenced the entire human genome, was completed in 2001 and cost 2.7 billion US dollars (International Human Genome Sequencing Consortium, 2001; Venter et al., 2001). Between the years of 2008 and 2017, the rate of decrease in cost of genetic sequencing, per megabase of deoxyribonucleic acid (DNA), has far surpassed Moore's Law, which describes the doubling rate of computer power and acts as a benchmark for technological success. As DNA sequencing costs become ever more affordable and genetic data becomes more accessible, marketing researchers and practitioners will have the ability to understand potential genetic influences on consumer behavior. To date, there is a dearth of research linking genes and behavior, particularly in the applied behavior sciences. Of specific interest to consumer neuroscientists is variation in genes coding for neurochemicals. That is, because there is a pool of research exploring the neural pathways that influence behavioral marketing outcomes, it can be reasoned that variation in genes related to the synthesis, activation, transmission, or transportation molecules within a given neural pathway should too influence behavior. Of the limited research using genetic techniques to study behavior, most are candidate gene studies, investigating the role of a small subset of genes (typically 1-20 genes). In the sections that follow, we outline two mainstream techniques for studying the link between genes and behavior, and review research relevant to consumer psychology within each methodology. 


\subsection{1 | The candidate gene approach}

In social science, the candidate gene approach to genetic association employs specific hypotheses about the biological function of a gene, or a small subset of genes, and its variants subsequent effects on a given behavioral phenotype. For example, a number of studies have investigated how variation in exon III of the dopamine D4 receptor (DRD4) gene affects complex behaviors, including prosocial behavior (Sasaki et al., 2011), cultural value orientation (Kitayama et al., 2014), and postgame testosterone level following team-based games (Verbeke, Belschak, Bagozzi, \& De Rijke, 2015). This gene, DRD4, has a variable number tandem repeat in it, meaning that a small nucleotide sequence repeats a variable number of times across and within individuals (since individuals have two copies of DRD4, one from each parent) and provides a good example of how candidate gene studies are typically conducted. The variants of DRD4 are categorized by the number of repeats they have. In some candidate gene studies investigating the effects of $D R D 4$ variation, the 2-repeat (2R) and 7-repeat (7R) variants are lumped together and compared to all other variants. This way, $2 R / 7 R$ carriers can be compared as a measured independent variable with two levels (2R/7R carriers versus all other variants, i.e., 2R/7R noncarriers).

Simplicity, cost, and theoretical foundation are the most important advantages of candidate gene studies. The main disadvantage of many candidate gene studies conducted to date is their lack of statistical power. Given that behavioral phenotypes are distal outcome variables, relative to genetic processes, their direct effect on behavior (regardless of genetic variant type) is usually very small. Candidate gene studies typically use sample sizes under 1,000 (sometimes 100 or less). Recent statistical evidence suggests that these sample sizes are too small to adequately power genetic association studies and many candidate gene studies have now failed to replicate, are likely false positives, and have been the subject of publication bias (Beauchamp et al., 2011; Chabris et al., 2012). Importantly, as many candidate gene studies have failed to replicate, candidate gene studies have become increasingly difficult to publish, and journals have been prompted to release editorial policies detailing strict guidelines regulating the publication of genetic association studies (see Hewitt, 2011 and Little et al., 2009; for examples of such policies).

To illustrate the difficulty of conducting replications and interpreting findings in candidate gene studies, consider the following. Two dopamine receptor genes, DRD2 and the aforementioned DRD4, have been studied in marketing using a candidate gene approach and attempted conceptual replication of previous findings. In one study, with a sample of 65 salespersons, carriers of the $7 R^{+}$genetic variant of DRD4 had higher customer orientation than those with the $7 \mathrm{R}^{-}$variant, but no differences in customer orientation were found for carriers of DRD2 A2/A2 versus A1/A2, and A1/A1 (Bagozzi et al., 2012). Another study looking at main effects of variants of DRD2 and DRD4 for a sample of 144 salespersons found opposite results: carriers of certain $D R D 2$ variants had significant indirect effects on new product selling through performance of the task of knowledge brokering, whereas carriers of certain DRD4 variants, which had previously been associated with customer orientation, did not (van den Berg et al., 2014).
Based on the supposition that candidate genes by themselves might not produce consistent effects, a third study proposed and found that, for a sample of 65 salespersons, DRD4 carriers $7 \mathrm{R}^{+}$versus $7 R^{-}$interacted with the phenotype of psychological avoidant attachment style, and DRD2 carriers of A2/A2, versus A1/A2 and A1/ $A 1$, interacted with avoidant attachment style to positively influence customer orientation (Verbeke, Bagozzi, \& van den Berg, 2014). It is probably unreasonable to expect that candidate genes will have consistent main effects for complex behavioral phenotypes. Rather, their effects, if any, may depend on environmental or psychological conditions, comprising complex gene-by-environment interactions. In the case of gene-by-environment interactions, the necessary sample sizes for adequate statistical power are unclear, given prespecified hypotheses and (typically) dramatically lower phenotypic measurement error than genome-wide approaches.

\subsection{2 | Genome-wide association studies}

On the other end of the genetic association methodological continuum are genome-wide association studies (GWAS). Such studies use genome-wide genetic variation data, conservative control variables, and multiple testing correction to elucidate genetic associations with behavior, often in an a-theoretical manner. As the cost of genetic sequencing has decreased exponentially, GWAS have become increasingly popular and mainstream. In GWAS, millions of single nucleotide polymorphisms (SNPs), representing variation in genes from across the entire genome, are independently regressed on the behavioral phenotype of interest, typically using a minor allele dosage model (i.e., testing whether there is a linear pattern of association between the number of alleles of the less common variant and the dependent variable). Standard control variables, such as age, sex, the interaction of age and sex, and population stratification principle components created by conducting a genome-wide principal components analysis, are also included in the regressions (Benjamin et al., 2012; Price et al., 2006).

The primary advantage of GWAS is that, if conducted properly, the results are highly robust and replicable. Additionally, as GWAS are a top-down process, they can result in genetic associations that were not anticipated and may lead to fruitful future research avenues (e.g., when unexpected SNPs turn out to be significant, the biological function of these SNPs may not yet be known, resulting in motivation for more basic fields to study these genes at a molecular level). The largest drawback of GWAS, however, is their cost, as tens or hundreds of thousands of individuals are needed for adequate statistical power, and SNP arrays (which measure SNP variation) still cost several hundreds of dollars to purchase and have sequenced. Thus, at present, GWAS can only be conducted with large national or multinational research grants, which are typically awarded to research consortiums across multiple institutions (current GWAS frequently have over 50 authors on a publication), and their feasibility for consumer neuroscientists, and marketing academics in general, is limited. Additionally, GWAS to date have been limited in the quality of phenotypes that can be used to test theoretical processes. Table 2 provides a summary 
TABLE 2 Summary of pros and cons of candidate gene and GWAS approaches to genetic association

\begin{tabular}{ll} 
Candidate gene studies & \\
\hline Advantages & Disadvantages \\
- Theoretically driven & - Lack of statistical power and \\
- Potential biological relevance & replicability \\
- Relatively inexpensive & - High likelihood of false \\
(compared to GWAS) & positives and inability to rely on \\
- Can study a wider variety of & past findings in the literature as \\
constructs-researcher has & they may be underpowered \\
greater control of DV's and is & - Publication standards seem to \\
actively involved in data & be moving away from candidate \\
generation process & gene studies \\
- Can be used to make simple, & \\
easily interpreted and analyzed & \\
study designs &
\end{tabular}

of the advantages and disadvantages of candidate gene and GWAS approaches to genetic association studies.

\subsection{3 | Gene-by-environment interactions}

A gene-by-environment interaction $(\mathrm{G} \times \mathrm{E})$ occurs when two or more genotypes (at a given locus) respond differently to two or more different environments. A G $\times$ E interaction is a "situation in which genetic effects connected to a phenotype are dependent upon variability in the environment, or when genes modify an organism's sensitivity to environmental features" (Seabrook \& Avison, 2010, p. 1277). Note that the meaning of "environment" can encompass a situational manipulation or a phenotype such as a psychological trait or state. That is, the observed phenotype when an individual has genotype A only differs from the observed phenotype of an individual who has genotype $B$ if the phenotypes are expressed in a given environment.

Gene-by-environment studies typically use the candidate gene methodology, but, given an emphasis on the interaction as the primary contribution, require a richer foundation in social theory (than main effect genetic association studies) to drive the environmental component. Given the lack of feasibility of GWAS in marketing at present, $\mathrm{G} \times \mathrm{E}$ studies could provide early promise for marketers interested in the genetic influences of consumer behavior. Such potential exists because marketers utilizing neurophysiological measures are wellversed in consumer behavior and economic theory, which can provide the rich theoretical foundation necessary for $\mathrm{G} \times \mathrm{E}$ studies. Gene-bygene interactions can also be determinative of behavior (e.g., Verbeke, Bagozzi, van den Berg, Worm, \& Belschak, 2016).

The first high profile $\mathrm{G} \times \mathrm{E}$ publication was that of Caspi et al. (2002), in which variants of the serotonin-transporter-linked polymorphic region (5-HTTLPR; gene) were shown to interact with life stress (environment) to influence depression. Despite controversy over the validity and replicability of findings in Caspi et al. (e.g., Risch et al., 2009), this work spawned a great deal of $G \times E$ research in adjacent fields, including marketing. For example, Bagozzi and Verbeke (2018) conducted a study on how salespersons' hedonic systems (i.e., the neural reward circuit founded in wanting and liking) mediate the relationship between genotype and essential work-related tasks. Crucially,

\section{GWAS}

\section{Advantages}

- Robust, replicable results due to high methodological rigor (control variables and multiple testing correction)

- Becoming more prevalent in top-tier journals/acceptable standard of research

\section{Disadvantages}

- A-theoretical-significant SNPs can have no meaning initially

- Extremely expensive

- Lack of relevant data/ behavioral phenotypes for social science (most genetic consortium are primarily concerned with medical phenotypes)

- Computationally intensive the study used a three-way interaction between each of three candidate genes, DRD4, catechol-O-methyltransferase (COMT), and the oxytocin receptor gene (OXTR), adult psychological attachment styles (avoidant, anxious, or secure; Harms, 2011), and job stress. Results of this study indicated that among salespersons with an avoidant attachment style, DRD4 7R carriers are highly motivated in situations of high role conflict. In contrast, among salespersons with a secure attachment style, COMT Met/Met variant carriers are more motivated than other COMT variants in situations when there is low role conflict. Finally, Bagozzi and Verbeke (2018) provide evidence that OXTR had a main effect on job satisfaction; whereas an anxious attachment style and/or higher role conflict decreases job satisfaction, carrying certain variants of OXTR predisposes salespersons to greater job satisfaction.

Given the history of false positives in candidate gene approaches, it is absolutely essential that hypotheses in $\mathrm{G} \times \mathrm{E}$ studies be prespecified, and all results, including nonsignificant findings, be disclosed so that meta-analyses can later be conducted. Additionally, replication studies must be conducted, and all studies should be conducted according to the strict guidelines in Hewitt (2011) and Little et al. (2009). The caveats of $G \times E$ studies are similar to those of candidate gene studies (Ordovas \& Tai, 2008). First, $G \times E$ studies suffer from low power and publication bias. Second, just like genetic factors, environmental factors are co-linear with other environmental factors, so establishing causation is difficult and even significant results should be analyzed with caution. Third, although genotyping provides precise measurement, measurement of complex behaviors and behavioral phenotypes has significant measurement error (an issue that is pervasive throughout behavioral research but does not receive enough attention).

\section{3 | Social contexts and neuroscience}

Many consumer decisions are made within a social context (e.g., purchases made with others; buying in interaction with salespeople), or with a social context looming (e.g., purchases that are made online but the product is consumed in public). Social settings have dramatic implications for choice and behavior. Yet, much laboratory research is conducted in isolation from social context. For this reason, Pozharliev, 
Verbeke, and Bagozzi (2017) argue for the importance of the inclusion of social contexts in studies using neurophysiological measures. Of particular relevance to understanding how social situations influence consumption and other marketing relevant research areas is how the individual perceives others' thoughts about the situation and uses this information to influence their own thoughts. Research in neuroscience on theory of mind, empathy, and other processes (outlined previously) can be used to lay the foundation for appreciating social consumption contexts in marketing. Pozharliev, Verbeke, van Strien, and Bagozzi (2015) found, for example, that greater attention was allocated to viewing luxury brands and greater motivational/emotional reactions occurred for people observing such brands when in the presence of another person versus alone. These attentional and emotional differences in social situations can largely be explained by social facilitation theory, which is one of the views that neuroscience studies in consumer research could utilize to study social processes, rather than limiting research to observing individuals in isolation.

As an example of how consumer neuroscientists can leverage novel techniques while also incorporating social context, Bagozzi, Stornelli, Verbeke, Bagozzi, and Chakrabarti (2018) found that both empathetic concern and perspective taking are influenced by the interaction between incidental human touch and the COMT gene. That is, (yet to be published study) a $\mathrm{G} \times \mathrm{E}$ interaction occurred such that empathy increased when subjects were touched briefly on the shoulder (a highly social context) and possessed the Met/Met variant of COMT, versus not being touched and having Met/Val or Val/Val variants. Empathy then leads to trust as a psychological state, and trust, in turn, influenced actual behavior in the economic centipede game.

Another (yet to be published) study illustrating how social context can be incorporated into neurophysiological research in marketing investigated competition and cooperation in the centipede game. Bagozzi, Stornelli, Verbeke, Bagozzi, Chakrabarti, et al. (2018) found that oxytocin interacts with psychological attachment styles to influence empathetic concern. In this gene-by-phenotype interaction, a positive association was found between oxytocin and the anxious attachment style to influence empathetic concern, such that subjects with the GG variant of a SNP within the oxytocin gene, but not AG and AA variants, had greater empathetic concern, the greater the anxious attachment style. Likewise, a positive interaction occurred between oxytocin and the avoidance attachment style, such that subjects with the GG variant within the oxytocin gene, but not $A G$ and $A A$ variants, had greater empathetic concern, the greater the avoidant attachment style. Finally, secure attachment style had a main effect on empathetic concern, while oxytocin gene variant neither interacted with secure attachment nor had a main effect. The above-mentioned oxytocin by anxious and oxytocin by avoidant interaction effects had significant conditional indirect effects on actual game behavior through empathetic concern and trust, whereas secure attachment affected actual behavior through the serial mediation of empathetic concern and trust.

Emerging research, such as that detailed investigating the effects of neuromolecule-related genetic variants and hormonal processes, shows how social contexts can be integrated into consumer neuroscience. Methods and tools from consumer neuroscience, in conjunction with environmental factors and psychological variables, will be critical in providing insight into contingencies that undergird the facilitating and inhibiting forces in social behavior.

\section{4 | Consciousness}

Many neuroscience studies in consumer behavior and marketing, and the wider neuroscience literature, begin with a manipulation of conditions designed to induce changes in mental states or events, and then measure activation of relevant brain regions by such methods as fMRI as the primary dependent variables of interest. Such an approach implicitly focuses on psychological processes as third-person phenomena, which is consistent with the prevailing point of view of reductionism held by most neuroscientists and researchers in basic and applied disciplines using neuroscience methods. Typically, a variant of functionalism underpins such approaches (Bagozzi \& Lee, 2017).

Such reductionist approaches address what can be termed as folk psychology processes, which are regarded as immature vestiges of evolving disciplines, and proceed from the assumption that physical processes will eventually replace folk psychology. By contrast, some researchers presume that first-person processes (singular and plural) and second-person processes are those that allow people to achieve meaning in their lives and function at a different level of discourse than presumed by third-person perspectives. In contrast to reductionist approaches, first- and second-person processes cannot be reduced to simple physical/chemical processes between neurons. Hard core reductionists, of which the vast majority of researchers in neuroscience can be classified (if not explicitly, then at least by the implicit point of view taken in their research), follow a metaphysical orientation, which can be termed reductive functionalism, or even eliminativism. Conversely, researchers retaining a role for subjective interpretation in their research participants follow emergentism, nonreductive functionalism, classic dualism, or naturalistic dualism (see Bagozzi \& Lee, 2017; for a review and analyses of the different points of view). A rapidly developing, more-or-less intermediary position claims that subjective experiences are produced by physical processes in the brain (see Bagozzi \& Lee, 2017, for a discussion and illustration of the latter). For example, subjective pleasure has been argued to be produced by unconscious neuroprocesses in the wanting and liking systems.

Some researchers have advocated that to represent first- and second-person processes within a neuroscience context, explicit subjective reports or interpretations must be included in any neuroscience study (Bagozzi \& Lee, 2017). For example, theory of mind, empathy, and Machiavellianism neural substrates have been successfully related to psychological scales shown to validly capture theory of mind, empathetic, and Machiavellianism processes, respectively (Bagozzi et al., 2012, 2013; Dietvorst et al., 2009). Such approaches represent multilevel investigations in which different levels of analysis (e.g., activation of regions of the brain and self-report measures) correspond to manipulations shown to reflect underlying theorizing and have been related formally through correlation or regression analyses. Alternative approaches to multilevel investigations of consciousness can be done using concepts such as supervenience and emergence. Bagozzi and 
Lee (2017, Figure 8) develop the arguments supporting such perspectives, as well as outline a general philosophy of mind framework applied to folk psychology explanations of action, grounded in neuroscience and subjective measurements.

Researchers using neuroscience methods and tools must come to grips with the qualitative or subjective experiences of the phenomena under study if they are to account for human experience and the meaning it has for the people having such experiences. The fullest explanations of consumer and managerial behavior, it may be claimed, will require frameworks integrating neuroscience measurements with subjective interpretations; the most fruitful and insightful conclusions will likely be drawn when methods are combined, such that the shortcomings of one methodology are offset by the strengths of another (Venkatraman et al., 2015).

\subsection{Common caveats of consumer neuroscience}

Given the novelty of research and practice combining neuroscience and marketing, several key caveats are worthy of discussion. First, there is currently an fMRI-biased methodological dogma throughout consumer neuroscience studies. Second, event-based study designs fail to appreciate non-stimulus-based neural responses. Third, the issue of reverse inference should be carefully considered. Finally, consumer neuroscience suffers from perceptions of low reliability and generalizability.

As detailed in the Neuroscience Methods and Tools section (and Table 1), neuroscientists have a wide variety of methodological approaches at their disposal to study the brain and behavior. Thus far in marketing, however, fMRI studies have dominated published works. Although fMRI has been the stable workhorse of research in consumer neuroscience, there is currently perhaps too much reliance on fMRI within the field; many designs and concepts in consumer research do not necessitate $\mathrm{fMRI}$, and $\mathrm{fMRI}$ is not without its drawbacks, which primarily include multiple comparisons (Vul, Harris, Winkielman, \& Pashler, 2009) and systematic software issues (Eklund, Nichols, \& Knutsson, 2016). Many other neuroscientific techniques are available to researchers in marketing and should be utilized for their unique advantages based on the nature of the research question and for the goal of establishing convergent and discriminant validity of concepts and processes across different methods.

Event- or stimulus-based designs are traditional controlled experimental designs in which participants are exposed to a stimulus, and brain activity is measured in response to, or concurrently, with that stimulus and a behavioral response. Such designs are popular because they follow the logical temporal sequence with which lay beliefs hold that mental processes occur (i.e., an event occurs, and the participant responds to that event, in that order). Likewise, most philosophy of science perspectives on causality follows such an interpretation (e.g., Dowe, 2008; Schaffer, 2016; Woodward, 2016). However, such designs have been criticized for characterizing the brain as a reactive system. That is, event-based designs impose a temporal order on how the brain processes information, which some evidence suggests is not always the case. Namely, resting state brain activity appears to be more meaningful than once thought, and intrinsic/endogenous or default mode brain activity plays a role in stimulus-based responses. Resting brain activity has been shown to utilize the same amount of bodily energy as stimulus-based responses (Raichle \& Mintun, 2006), which implies that stimulusresponse brain activity is a redistribution of energy rather than a heightening of energy use, per se (as event-based designs often imply). Additionally, prestimulus endogenous brain activity appears to influence attention, perception, memory, and ultimately decisionmaking, which in turn interacts with stimuli to create significant variability in the responses of event-based designs (Braeutigam, Lee, \& Senior, 2017; Huang et al., 2017). For this reason, consumer neuroscience could benefit from the incorporation and appreciation of prestimulus endogenous brain activity and a lesser reliance on event-based designs.

Reverse inference is a logical fallacy that is believed to be everpresent throughout neuroscience and subsequently across applied fields such as consumer neuroscience and neuromarketing. Poldrack (2006) goes as far as to call the issue of reverse inference in neuroscience an "epidemic of reasoning." A reverse inference occurs when one reasons backwards from observed brain activity to cognitive process (Poldrack, 2006). That is, when conducting a study aimed at investigating a given cognitive process, brain area $\mathrm{X}$ is observed to be active. In another study aimed at investigating a different cognitive process, brain area $\mathrm{X}$ is also observed to be active, during a different task. Reverse inference occurs when the first study concludes that the cognitive process from the second study is occurring, because the same brain area, $\mathrm{X}$, was observed to be active, even though the second cognitive process was not initially hypothesized or intended to be part of the experimental design of the first study. Such reasoning is problematic because one is inferring that a cognitive process is occurring, even though it was not directly observed (Lee, Brandes, Chamberlain, \& Senior, 2017).

Finally, a classic lay critique of neuroscientific findings is that they are unreliable, do not generalize, or have a high likelihood of false positives due to the fact that they use smaller sample sizes than typical behavioral studies. These claims, however, are largely uninformed and can be dispelled. First, neuroimaging studies are typically within-subject, so sample sizes within a given treatment cell, usually 30-50 participants, are comparable to behavioral studies with between subject designs. Second, in terms of generalizability, neuroimaging studies typically have the same nonrepresentation problems that other studies within marketing have, which is a reliance on Western, educated, industrialized, rich, and democratic samples (i.e., samples largely collected using undergraduate student participants; Henrich, Heine, \& Norenzayan, 2010). However, as mentioned previously, and contrary to critical lay beliefs, evidence from neuroforecasting research suggests that neural data may actually be more generalizable to the population than behavioral data alone. Lastly, the threat of false positives in neuroscientific research is valid; however, such is the case for research from across all of the behavioral sciences. Such issues of replicability are not unique to neuroscience and present a significant challenge to scientific progress as a whole. 
To combat opportunistic findings, we, as scientists, must uphold standards of quality and integrity in research; replication studies and meta-analysis should be valued highly for their contributions toward scientific progress.

\section{6 | SUMMARY AND CONCLUSIONS}

In this article, we have presented a selective overview of neuroscience and marketing. In doing so, we reviewed foundational research from neuroscience on which consumer research builds and discussed exemplary contributions from consumer neuroscience. Next, the neuroscientific tools available to marketers were briefly discussed, and several avenues for future research were considered, including the need for integrative approaches across theories in consumer psychology, genetic association studies, and common limitations of using neuroscientific methods.

With a critical mass of researchers conducting work at top academic institutions and publishing in top-tier marketing and nonmarketing journals, the field of consumer neuroscience is poised to continue to develop, expand, and add value to the field of marketing as a whole. Neuroscientific findings provide unique information about the consumer that cannot otherwise be observed using traditional behavioral approaches. The use of neuroscientific theory and methods, and more broadly, psychophysiological approaches, has added and will continue to add, considerable unique value to the field of marketing. Ultimately, neuropsychological findings are essential to scientific pursuits attempting to unravel the foundational processes underlying consumer behavior, and to the progression of scientific knowledge in marketing.

\section{REFERENCES}

Aaker, J. L. (1997). Dimensions of brand personality. Journal of Marketing Research, 34(3), 347-356.

Aaker, J., \& Fournier, S. (1995). A brand as a character, a partner and a person: Three perspectives on the question of brand personality. In F. R. Kardes \& M. Sujan (Eds.), NA - Advances in consumer research (Vol. 22, pp. 391-395). Provo, UT: Association for Consumer Research.

Adolphs, R. (2010). Conceptual challenges and directions for social neuroscience. Neuron, 65(6), 752-767.

Arias-Carrión, O., Stamelou, M., Murillo-Rodríguez, E., Menéndez-González, M., \& Pöppel, E. (2010). Dopaminergic reward system: A short integrative review. International Archives of Medicine, 3(24), 1-6.

Armstrong, K. M., Fitzgerald, J. K., \& Moore, T. (2006). Changes in visual receptive fields with microstimulation of frontal cortex. Neuron, 50(5), 791-798.

Azoulay, A., \& Kapferer, J.-N. (2003). Do brand personality scales really measure brand personality? Brand Management, 11(2), 143-155.

Baddeley, A. (2017). Working memory, thought, and action. Oxford, UK: Oxford University Press.

Bagozzi, R. P. (1991). The role of psychophysiology in consumer research. In T. S. Robertson \& H. H. Kassarjian (Eds.), Handbook of consumer behavior (pp. 124-161). Englewood Cliffs, NJ: Prentice-Hall.

Bagozzi, R. P., \& Lee, N. (2017). Philosophical foundations of neuroscience in organizational research: Functional and nonfunctional approaches. Organizational Research Methods, https://doi.org/10.1177/1094428117697042
Bagozzi, R. P., Stornelli, J., Verbeke, W., Bagozzi, B. E., \& Chakrabarti, A. (2018). Molecular genetics, phenotypes, and the explanation of competition and cooperation in economic games. Unpublished working paper.

Bagozzi, R. P., Stornelli, J., Verbeke, W., Bagozzi, B. E., Chakrabarti, A., \& $\mathrm{Vu}, \mathrm{T}$. (2018). Competition and cooperation in centipede games: Biology matters, but so do the environment and self-consciousness. Unpublished working paper.

Bagozzi, R. P., \& Verbeke, W. J. M. I. (2018). Genetic and psychological underpinnings of salesforce behavior and their role in generating task actions. Paper under review.

Bagozzi, R. P., Verbeke, W. J. M. I., Dietvorst, R. C., Belschak, F. D., van den Berg, W. E., \& Rietdijk, W. J. R. (2013). Theory of mind and empathic explanations of Machiavellianism. Journal of Management, 39(7), 1760-1798.

Bagozzi, R. P., Verbeke, W. J. M. I., van den Berg, W. E., Rietdijk, W. J. R., Dietvorst, R. C., \& Worm, L. (2012). Genetic and neurological foundations of customer orientation: Field and experimental evidence. Journal of the Academy of Marketing Science, 40(5), 639-658.

Beauchamp, J. P., Cesarini, D., Johannesson, M., van der Loos, M. J. H. M., Koellinger, P. D., Groenen, P. J. F., ... Christakis, N. A. (2011). Molecular genetics and economics. Journal of Economic Perspectives, 25(4), 57-82.

Benjamin, D. J., Cesarini, D., Chabris, C. F., Glaeser, E. L., Laibson, D. I., Guonason, V., ... Lichtenstein, P. (2012). The promises and pitfalls of genoeconomics. Annual Review of Economics, 4(1), 627-662.

van den Berg, W. E., Verbeke, W., Bagozzi, R. P., Worm, L., de Jong, A. A., \& Nijssen, E. (2014). Salespersons as internal knowledge brokers and new products selling: Discovering the link to genetic makeup. Journal of Product Innovation Management, 31(4), 695-709.

Berns, G. S., \& Moore, S. E. (2012). A neural predictor of cultural popularity. Journal of Consumer Psychology, 22, 154-160.

Berridge, K. C. (1996). Food reward: Brain substrates of wanting and liking. Neuroscience and Biobehavioral Reviews, 20(1), 1-25.

Berridge, K. C. (2009). Wanting and liking: Observations from the neuroscience and psychology laboratory. Inquiry, 52(4), 378-398.

Berridge, K. C., \& Kringelbach, M. L. (2015). Pleasure systems of the brain. Neuron, 86(3), 646-664.

Berridge, K. C., Robinson, T. E., \& Aldridge, J. W. (2009). Dissecting components of reward: 'liking', 'wanting', and learning. Current Opinion in Pharmacology, 9(1), 65-73.

Bliss, T. V., \& Collingridge, G. L. (1993). A synaptic model of memory: Longterm potentiation in the hippocampus. Nature, 361, 31-39.

Bloch, P. H. (1995). Seeking the ideal form: Product design and consumer response. Journal of Marketing, 59(3), 16-29.

Braeutigam, S., Lee, N., \& Senior, C. (2017). A role for endogenous brain states in organizational research. Organizational Research Methods, 7 , $1-22$.

Bush, G., Luu, P., \& Posner, M. I. (2000). Cognitive and emotional influences in anterior cingulate cortex. Trends in Cognitive Sciences, 4(6), 215-222.

Camerer, C., Loewenstein, G., \& Prelec, D. (2005). Neuroeconomics: How neuroscience can inform economics. Journal of Economic Literature, 43(1), 9-64.

Camerer, C., \& Yoon, C. (2015). Introduction to the journal of marketing research special issue on neuroscience and marketing. Journal of Marketing Research, 52, 423-426.

Caspi, A., McClay, J., Moffitt, T. E., Mill, J., Martin, J., Mill, J., ... Poulton, R. (2002). Role of genotype in the cycle of violence in maltreated children. Science, 297(5582), 851-854.

Chabris, C. F., Hebert, B. M., Benjamin, D. J., Beauchamp, J., Cesarini, D., van der Loos, M., ... Poulton, R. (2012). Most reported genetic associations with general intelligence are probably false positives. Psychological Science, 23(11), 1314-1323.

Christianson, S.-A. (1992). The handbook of emotion and memory: Research and theory. Hillsdale, $\mathrm{NJ}$ : Erlbaum.

Connor, C. E., Egeth, H. E., \& Yantis, S. (2004). Visual attention: Bottom-up versus top-down. Current Biology, 14, R850-R852. 
Cook, E. P., \& Maunsell, J. H. (2002). Attentional modulation of behavioral performance and neuronal responses in middle temporal and ventral intraparietal areas of macaque monkey. Journal of Neuroscience, 22(5), 1994-2004.

Corbetta, M., \& Shulman, G. L. (2002). Control of goal-directed and stimulus-driven attention in the brain. Nature Reviews Neuroscience, 3 , 201-215.

Coricelli, G., Critchley, H. D., Joffily, M., O'Doherty, J. P., Sirigu, A., \& Dolan, R. J. (2005). Regret and its avoidance: A neuroimaging study of choice behavior. Nature Neuroscience, 8(9), 1255-1262.

Dapretto, M., Davies, M. S., Pfeifer, J. H., Scott, A. A., Sigman, M., Bookheimer, S. Y., \& lacoboni, M. (2006). Understanding emotions in others: Mirror neuron dysfunction in children with autism spectrum disorders. Nature Neuroscience, 9(1), 28-30.

Decety, J., \& Lamm, C. (2006). Human empathy through the lens of social neuroscience. The Scientific World Journal, 6, 1146-1163.

Deppe, M., Schwindt, W., Kugal, H., Plassmann, H., \& Kenning, P. (2005) Nonlinear responses within the medial prefrontal cortex reveal when specific implicit information influences economic decision making. Journal of Neuroimaging, 15(2), 171-182.

Deppe, M., Schwindt, W., Pieper, A., Kugel, H., Plassmann, H., Kenning, P., ... Ringelstein, E. B. (2007). Anterior cingulate reflects susceptibility to framing during attractiveness evaluation. NeuroReport, 18(11), 1119-1123.

Dietvorst, R. C., Verbeke, W. J. M. I., Bagozzi, R. P., Yoon, C., Smits, M., \& van der Lugt, A. (2009). A sales force specific theory-of-mind scale: Tests of its validity by classical methods and functional magnetic resonance imaging. Journal of Marketing Research, 46, 653-668.

Dowe, P. (2008). Causal processes. In E. N. Zalta (Ed.), The Stanford encyclopedia of philosophy (Fall 2008 Edition). https://plato.stanford.edu/ entries/causation-process/

Doyon, J., Laforce, R. Jr, Bouchard, G., Gaudreau, D., Roy, J., Poirier, M., ... Bouchard, J.-P. (1998). Role of the striatum, cerebellum and frontal lobes in the automatization of a repeated visuomotor sequence of movements. Neuropsychologia, 36(7), 625-641.

Duncan, J., \& Humphreys, G. W. (1989). Visual search and stimulus similarity. Psychological Review, 96(3), 433-458.

Durgin, F. H., Doyle, E., \& Egan, L. (2008). Upper-left gaze bias reveals competing search strategies in a reverse Stroop task. Acta Psychologica, 127(2), 428-448.

Efron, R., \& Yund, E. W. (1996). Spatial nonuniformities in visual search. Brain and Cognition, 31(3), 331-368.

Eichenbaum, H. (1994). The hippocampal system and declarative memory in humans and animals: Experimental analysis and historical origins. In D. L. Schacter \& E. Tulving (Eds.), Memory systems (pp. 147-201). Cambridge, MA: MIT Press.

Eichenbaum, H. (2000). A cortical-hippocampal system for declarative memory. Nature Reviews Neuroscience, 1, 41-50.

Eklund, A., Nichols, T. E., \& Knutsson, H. (2016). Cluster failure: Why fMRI inferences for spatial extent have inflated false-positive rates. Proceedings of the National Academy of Sciences, 113(28), 7900-7905.

Ekman, P. (1992). An argument for basic emotions. Cognition \& Emotion, 6(3/4), 169-200.

Ekman, P. (1999). Basic emotions. In T. Dalgleish \& M. Power (Eds.), Handbook of cognition and emotion (pp. 45-60). Sussex, UK: John Wiley $\&$ Sons.

Erk, S., Spitzer, M., Wunderlich, A. P., Galley, L., \& Walter, H. (2002). Cultural objects modulate reward circuitry. NeuroReport, 13(18), 2499-2503.

Esch, F.-R., Möll, T., Schmitt, B., Elger, C. E., Neuhaus, C., \& Weber, B. (2012). Brands on the brain: Do consumers use declarative information or experienced emotions to evaluate brands? Journal of Consumer Psychology, 22, 75-85.

Falk, E. B., Berkman, E. T., \& Lieberman, M. D. (2012). From neural responses to population behavior: Neural focus group predicts population-level media effects. Psychological Science, 23(5), 439-445.
Felleman, D. J., \& Van Essen, D. C. (1991). Distributed hierarchical processing in the primate cerebral cortex. Cerebral Cortex, 1, 1-47.

Fields, H. L., Hjelmstad, G. O., Margolis, E. B., \& Nicola, S. M. (2007). Ventral tegmental area neurons in learned appetitive behavior and positive reinforcement. Annual Review of Neuroscience, 30(1), 289-316.

Fliessbach, K., Weber, B., Trautner, P., Dohmen, T., Sunde, U., Elger, C. E., \& Falk, A. (2007). Social comparison affects reward-related brain activity in the human ventral striatum. Science, 318, 1305-1308.

Frith, C. D., \& Frith, U. (2006). The neural basis of mentalizing. Neuron, 50(4), 531-534.

Frith, C. D., \& Frith, U. (2008). Implicit and explicit processes in social cognition. Neuron, 60, 503-510.

Fugate, D. L. (2007). Neuromarketing: A layman's look at neuroscience and its potential application to marketing practice. Journal of Consumer Marketing, 24(7), 385-394.

van der Gaag, C., Minderaa, R. B., \& Keysers, C. (2007). Facial expressions: What the mirror neuron system can and cannot tell us. Social Neuroscience, 2(3-4), 179-222.

Gallese, V. (2003). The manifold nature of interpersonal relations: The quest for a common mechanism. Philosophical Transactions of the Royal Society B: Biological Sciences, 358, 517-528.

Genevsky, A., Yoon, C., \& Knutson, B. (2017). When brain beats behavior: Neuroforecasting crowdfunding outcomes. Journal of Neuroscience, 37(36), 8625-8634.

Gold, P. E., \& Van Buskirk, R. B. (1975). Facilitation of time-dependent memory processes with posttrial epinephrine injections. Behavioral Biology, 13, 145-153.

Harms, P. D. (2011). Adult attachment styles in the workplace. Human Resource Management Review, 21, 285-296.

Hauser, J. R., \& Wernerfelt, B. (1990). An evaluation cost model of consideration sets. Journal of Consumer Research, 16(4), 393-408.

Henrich, J., Heine, S. J., \& Norenzayan, A. (2010). The weirdest people in the world? Behavioral and Brain Sciences, 33(2-3), 61-135.

Hewitt, J. K. (2011). Editorial policy on candidate gene association and candidate gene-by-environment interaction studies of complex traits. Behavior Genetics, 42(1), 1-2.

Holbrook, M. B., \& Schindler, R. M. (1989). Exploratory findings on the development of musical tastes. Journal of Consumer Research, 16(1), 119-124.

Hsu, M., \& Yoon, C. (2015). The neuroscience of consumer choice. Current Opinion in Behavioral Sciences, 5, 116-121.

Huang, Z., Zhang, J., Longtin, A., Dumont, G., Duncan, N. W., Pokorny, J., ... Northoff, G. (2017). Is there a nonadditive interaction between spontaneous and evoked activity? Phase-dependence and its relation to the temporal structure of scale-free brain activity. Cerebral Cortex, 27(2), 1037-1059.

Hubert, M., \& Kenning, P. (2008). A current overview of consumer neuroscience. Journal of Consumer Behaviour, 7(4-5), 272-292.

Huddleston, P., Behe, B. K., Minahan, S., \& Fernandez, R. T. (2015). Seeking attention: An eye tracking study of in-store merchandise displays. International Journal of Retail \& Distribution Management, 43(6), 561-574.

lacoboni, M. (2009). Imitation, empathy, and mirror neurons. Annual Review of Psychology, 60(1), 653-670.

International Human Genome Sequencing Consortium (2001). Initial sequencing and analysis of the human genome. Nature, 409, 860-921.

Jabbi, M., Bastiaansen, J., \& Keysers, C. (2008). A common anterior insula representation of disgust observation, experience and imagination shows divergent functional connectivity pathways. PLOS ONE, 3(8), e2939.

Kaas, J. H. (2008). The evolution of the complex sensory and motor systems of the human brain. Brain Research Bulletin, 75, 384-390.

Karmarkar, U. R., Shiv, B., \& Knutson, B. (2015). Cost conscious? The neural and behavioral impact of price primacy on decision making. Journal of Marketing Research, 52(4), 467-481. 
Kastner, S., \& Ungerleider, S. (2000). Mechanisms of visual attention in the human cortex. Annual Review of Neuroscience, 23, 315-341.

Kenning, P. H., \& Plassmann, H. (2008). How neuroscience can inform consumer research. IEEE Transactions on Neural Systems and Rehabilitation Engineering, 16(6), 532-538.

Kenning, P., Plassmann, H., \& Ahlert, D. (2007). Applications of functional magnetic resonance imaging for market research. Qualitative Market Research: An International Journal, 10(2), 135-152.

Kim, H.-Y., Shin, Y., \& Han, S. (2014). The reconstruction of choice value in the brain: A look into the size of consideration sets and their affective consequences. Journal of Cognitive Neuroscience, 26(4), 810-824.

Kitayama, S., King, A., Yoon, C., Tompson, S., Huff, S., \& Liberzon, I. (2014). The dopamine $\mathrm{d} 4$ receptor gene (DRD4) moderates cultural difference in independent versus interdependent social orientation. Psychological Science, 25(6), 1169-1177.

Klucharev, V., Smidts, A., \& Fernández, G. (2008). Brain mechanisms of persuasion: How "expert power" modulates memory and attitudes. Social Cognitive and Affective Neuroscience, 3(4), 353-366.

Knutson, B., Adams, C., Fong, G., Walker, J., \& Hommer, D. (2001). Anticipation of increasing monetary reward selectively recruits nucleus accumbens. Journal of Neuroscience, 21(6), 1-5.

Knutson, B., Rick, S., Wimmer, G. E., \& Prelec, D. (2007). Neural predictors of purchases. Neuron, 53(1), 147-156.

Knutson, B., \& Wimmer, G. E. (2007). Reward: Neural circuitry for social valuation. In E. Harmon-Jones \& P. Winkielman (Eds.), Social neuroscience: Integrating biological and psychological explanations of social behavior (pp. 157-175). New York, NY: Guilford Press.

Koch, C. (2004). The quest for consciousness: A neurobiological approach. Englewood, CO: Roberts and Publishers.

Koenigs, M., \& Tranel, D. (2008). Prefrontal cortex damage abolishes brand-cued changes in cola preference. Social Cognitive and Affective Neuroscience, 3(1), 1-6.

Kringelbach, M. L., \& Berridge, K. C. (2012). The joyful mind. Scientific American, 307, 40-45.

LeDoux, J. E. (2000). Emotion circuits in the brain. Annual Review of Neuroscience, 23(1), 155-184.

LeDoux, J. (2015). Anxious. New York, NY: Viking.

Lee, N., Brandes, L., Chamberlain, L., \& Senior, C. (2017). This is your brain on neuromarketing: Reflections on a decade of research. Journal of Marketing Management, 33(11-12), 878-892.

Lee, N., Broderick, A. J., \& Chamberlain, L. (2007). What is "neuromarketing?" A discussion and agenda for future research. International Journal of Psychophysiology, 63(2), 199-204.

Lieberman, M. D. (2010). Social cognitive neuroscience. In S. T. Fiske, D. T. Gilbert, \& G. Linszey (Eds.), Handbook of social psychology (5th edn, pp. 143-193). New York, NY: McGraw-Hill.

Lindquist, K. A., Wager, T. D., Kober, H., Bliss-Moreau, E., \& Barrett, L. F. (2012). The brain basis of emotion: A meta-analytic review. Behavioral and Brain Sciences, 35, 121-143.

Little, J., Higgins, J. P. T., loannidis, J. P. A., Moher, D., Gagnon, F., Elm, E. V., ... Birkett, N. (2009). Strengthening the reporting of genetic association studies (STREGA) - An extension of the STROBE statement. PLoS Medicine, 6(2), e1000022.

Luck, S. J., Chelazzi, L., Hillyard, S. A., \& Desimone, R. (1997). Neural mechanisms of spatial selective attention in areas $\mathrm{V} 1, \mathrm{~V} 2$, and $\mathrm{V} 4$ of macaque visual cortex. Journal of Neurophysiology, 77(1), 24-42.

Lynch, M. A. (2004). Long-term potentiation and memory. Physiological Reviews, 84(1), 87-136.

Mahler, S. V., Smith, K. S., \& Berridge, K. C. (2007). Endocannabinoid hedonic hotspot for sensory pleasure: Anandamide in nucleus accumbens shell enhances "liking" of a sweet reward. Neuropsychopharmacology, 32(11), 2267-2278.

McAlister, A. R., \& Cornwell, T. B. (2010). Children's brand symbolism understanding: Links to theory of mind and executive functioning. Psychology \& Marketing, 27(3), 203-228.
McClure, S. M., Li, J., Tomlin, D., Cypert, K. S., Montague, L. M., \& Montague, P. R. (2004). Neural correlates of behavioral preference for culturally familiar drinks. Neuron, 44(2), 379-387.

McDonald, R. J., \& White, N. M. (1993). A triple dissociation of memory systems: Hippocampus, amygdala, and dorsal striatum. Behavioral Neuroscience, 107(1), 3-22.

McGaugh, J. L. (2000). Memory-A century of consolidation. Science, 287, 248-251.

Miller, G. A. (1956). The magical number seven, plus or minus two some limits on our capacity for processing information. Psychological Review, 101(2), 343-352.

Milosavljevic, M., Navalpakkam, V., Koch, C., \& Rangel, A. (2012). Relative visual saliency differences induce sizable bias in consumer choice. Journal of Consumer Psychology, 22(1), 67-74.

Muller, J., Corodimas, K. P., Fridel, Z., \& LeDoux, J. E. (1997). Functional inactivation of the lateral and basal nuclei of the amygdala by muscimol infusion prevents fear conditioning to an explicit conditioned stimulus and to contextual stimuli. Behavioral Neuroscience, 111(4), 683-691.

Murphy, F. C., Nimmo-Smith, I., \& Lawrence, A. D. (2003). Functional neuroanatomy of emotions: A meta-analysis. Cognitive, Affective, \& Behavioral Neuroscience, 3(3), 207-233.

Murray, E. A. (2007). The amygdala, reward and emotion. Trends in Cognitive Sciences, 11(11), 489-497.

Nisbett, R. E., \& Wilson, T. D. (1977). Telling more than we can know: Verbal reports on mental processes. Psychological Review, 84(3), 231-259.

Noudoost, B., Chang, M. H., Steinmetz, N. A., \& Moore, T. (2010). Topdown control of visual attention. Current Opinion in Neurobiology, 20(2), 183-190.

Ordovas, J. M., \& Tai, E. S. (2008). Why study gene-environment interactions? Current Opinion in Lipidology, 19, 158-167.

Paal, T., \& Bereczkei, T. (2007). Adult theory of mind, cooperation, Machiavellianism: The effect of mindreading on social relations. Personality and Individual Differences, 43(3), 541-551.

Packard, M. G., Cahill, L., \& McGaugh, J. L. (1994). Amygdala modulation of hippocampal-dependent and caudate nucleus-dependent memory processes. Neurobiology, 91, 8477-8481.

Peciña, S., \& Berridge, K. C. (2005). Hedonic hot spot in nucleus accumbens shell: Where do $\mu$-opioids cause increased hedonic impact of sweetness? Journal of Neuroscience, 25(50), 11777-11786.

Pfaus, J. G. (2009). Pathways of sexual desire. The Journal of Sexual Medicine, 6, 1506-1533.

Phan, K. L., Wager, T., Taylor, S. F., \& Liberzon, I. (2002). Functional neuroanatomy of emotion: A meta-analysis of emotion activation studies in PET and fMRI. Neurolmage, 16(2), 331-348.

Pieters, R., \& Warlop, L. (1999). Visual attention during brand choice: The impact of time pressure and task motivation. International Journal of Research in Marketing, 16(1), 1-16.

Plassmann, H., Ambler, T., Braeutigam, S., \& Kenning, P. (2007). What can advertisers learn from neuroscience? International Journal of Advertising, 15(31), 151-175.

Plassmann, H., Kenning, P., \& Ahlert, D. (2007). Why companies should make their customers happy: The neural correlates of customer loyalty. In G. Fitzsimons \& V. Morwitz (Eds.), NA - Advances in consumer research (Vol. 34, pp. 735-739). Duluth, MN: Association for Consumer Research.

Plassmann, H., O'Doherty, J., \& Rangel, A. (2007). Orbitofrontal cortex encodes willingness to pay in everyday economic transactions. Journal of Neuroscience, 27(37), 9984-9988.

Plassmann, H., O'Doherty, J., Shiv, B., \& Rangel, A. (2008). Marketing actions can modulate neural representations of experienced pleasantness. Proceedings of the National Academy of Sciences, 105(3), 1050-1054.

Plassmann, H., Ramsøy, T. Z., \& Milosavljevic, M. (2012). Branding the brain: A critical review and outlook. Journal of Consumer Psychology, 22(1), 18-36. 
Plassmann, H., Venkatraman, V., Huettel, S., \& Yoon, C. (2015). Consumer neuroscience: Applications, challenges, and possible solutions. Journal of Marketing, 52(4), 427-435.

Poldrack, R. (2006). Can cognitive processes be inferred from neuroimaging data? Trends in Cognitive Sciences, 10(2), 59-63.

Pool, E., Sennwald, V., Delplanque, S., Brosch, T., \& Sander, D. (2016). Measuring wanting and liking from animals to humans: A systematic review. Neuroscience and Biobehavioral Reviews, 63, 124-142.

Pozharliev, R., Verbeke, W. J. M. I., \& Bagozzi, R. P. (2017). Social consumer neuroscience: Neurophysiological measures of advertising effectiveness in a social context. Journal of Advertising, 46(3), 351-362.

Pozharliev, R., Verbeke, W. J. M. I., van Strien, J. W., \& Bagozzi, R. P. (2015). Merely being with you increases my attention to luxury products: Using EEG to understand consumers emotional experience of luxury branded products. Journal of Marketing Research, 52, 546-558.

Preuschoff, K., Quartz, S. R., \& Bossaerts, P. (2008). Human insula activation reflects risk prediction errors as well as risk. Journal of Neuroscience, 28(11), 2745-2752.

Price, A. L., Patterson, N. J., Plenge, R. M., Weinblatt, M. E., Shadick, N. A., \& Reich, D. (2006). Principal components analysis corrects for stratification in genome-wide association studies. Nature Genetics, 38(8), 904-909.

Raichle, M. E., \& Mintun, M. A. (2006). Brain work and brain imaging. Annual Review of Neuroscience, 29(1), 449-476.

Redish, A. D., \& Mizumori, S. J. Y. (2015). Memory and decision making. Neurobiology of Learning and Memory, 117, 1-3.

Refai, R., \& Bagozzi, R. P. (in press). The use of electroencephalography (EEG) in marketing research. In L. T. Wright, L. Martinho, \& R. P. Bagozzi (Eds.), Routledge companion to marketing research. Abington, Oxfordshire, UK: Routledge.

Repacholi, B., \& Slaughter, V. (Eds.) (2003). Individual differences in theory of mind: Implications for typical and atypical development. Hove, E. Sussex, UK: Psychology Press.

Reutskaja, E., Nagel, R., Camerer, C., \& Rangel, A. (2011). Search dynamics in consumer choice under time pressure: An eye-tracking study. American Economic Review, 101(2), 900-926.

Rilling, J. K., \& Sanfey, A. G. (2011). The neuroscience of social decisionmaking. Annual Review of Psychology, 62(1), 23-48.

Risch, N., Herrell, R., Lehner, T., Liang, K.-Y., Eaves, L., Hoh, J., ... Merikangas, K. R. (2009). Interaction between the serotonin transporter gene (5-HTTLPR), stressful life events, and risk of depression. Journal of the American Medical Association, 301(23), 2462-2471.

Salamone, J. D., \& Correa, M. (2012). The mysterious motivational functions of mesolimbic dopamine. Neuron, 76(3), 470-485.

Sanfey, A. G., Rilling, J. K., Aronson, J. A., Nystrom, L. E., \& Cohen, J. G. (2003). The neural basis of economic decision-making in the ultimatum game. Science, 300, 1755-1758.

Sasaki, J. Y., Kim, H. S., Mojaverian, T., Kelley, L. D. S., Park, I. Y., \& Janušonis, S. (2011). Religion priming differentially increases prosocial behavior among variants of the dopamine D4 receptor (DRD4) gene. Social Cognitive and Affective Neuroscience, 8(2), 209-215.

Schaefer, M., Berens, H., Heinze, H.-J., \& Rotte, M. (2006). Neural correlates of culturally familiar brands of car manufacturers. Neurolmage, 31(2), 861-865.

Schaefer, M., \& Rotte, M. (2007a). Favorite brands as cultural objects modulate reward circuit. NeuroReport, 18(2), 141-145.

Schaefer, M., \& Rotte, M. (2007b). Thinking on luxury or pragmatic brand products: Brain responses to different categories of culturally based brands. Brain Research, 1165, 98-104.

Schaffer, J. (2016). The metaphysics of causation. In E. N. Zalta (Ed.), The Stanford encyclopedia of philosophy (Fall 2016 Edition). https://plato. stanford.edu/archives/fall2016/entries/causation-metaphysics/

Scheibehenne, B., Greifeneder, R., \& Todd, P. M. (2010). Can there ever be too many options? A meta-analytic review of choice overload. Journal of Consumer Research, 37(3), 409-425.
Seabrook, J. A., \& Avison, W. R. (2010). Genotype-environment interaction and sociology: Contributions and complexities. Social Science \& Medicine, 70, 1277-1284.

Shocker, A., Ben-Akiva, M., Boccara, B., \& Nedungadi, P. (1991). Consideration set influences on consumer decision-making and choice: Issues, models, and suggestions. Marketing Letters, 2(3), 181-197.

Skurnik, I., Yoon, C., Park, D. C., \& Schwarz, N. (2005). How warnings about false claims become recommendations. Journal of Consumer Research, 31, 713-724.

Smidts, A., Hsu, M., Sanfey, A. G., Boksem, M. A. S., Ebstein, R. B., Huettel, S. A., ... Yoon, C. (2014). Advancing consumer neuroscience. Marketing Letters, 25(3), 257-267.

Smith, K. S., \& Berridge, K. C. (2005). The ventral pallidum and hedonic reward: Neurochemical maps of sucrose "liking" and food intake. Journal of Neuroscience, 25(38), 8637-8649.

Smith, S. M., \& Vale, W. W. (2006). The role of the hypothalamic-pituitaryadrenal axis in neuroendocrine responses to stress. Dialogues in Clinical Neuroscience, 8(4), 383-395.

Solnais, C., Andreu-Perez, J., Sánchez-Fernández, J., \& Andréu-Abela, J. (2013). The contribution of neuroscience to consumer research: A conceptual framework and empirical review. Journal of Economic Psychology, 36, 68-81.

Somerville, L. H., \& Casey, B. J. (2010). Developmental neurobiology of cognitive control and motivational systems. Current Opinion in Neurobiology, 20(2), 236-241.

Sperling, G. (1963). A model for visual memory tasks. Human Factors, 5(1), 19-31.

Squire, L. R., Knowlton, B., \& Musen, G. (1993). The structure and organization of memory. Annual Reviews of Psychology, 44, 453-495.

Stallen, M., Smidts, A., Rijpkema, M., Smit, G., Klucharev, V., \& Fernández, G. (2010). Celebrities and shoes on the female brain: The neural correlates of product evaluation in the context of fame. Journal of Economic Psychology, 31(5), 802-811.

Stellwagen, K. K., \& Kerig, P. K. (2013). Dark triad personality traits and theory of mind among school-age children. Personality and Individual Differences, 54(1), 123-127.

Tatler, B. W. (2007). The central fixation bias in scene viewing: Selecting an optimal viewing position independently of motor biases and image feature distributions. Journal of Vision, 7(14), 1-17.

Treisman, A. M., \& Gelade, G. (1980). A feature-integration theory of attention. Cognitive Psychology, 12, 97-136.

Ungerleider, L. G., \& Haxby, J. V. (1994). 'What' and 'where' in the human brain. Current Opinion in Neurobiology, 4, 157-165.

Venkatraman, V., Dimoka, A., Pavlou, P. A., Vo, K., Hampton, W., Bollinger, B., ... Winer, R. S. (2015). Predicting advertising success beyond traditional measures: New insights from neurophysiological methods and market response modeling. Journal of Marketing Research, 52, 436-452.

Venter, J. C., Adams, M. D., Myers, E. W., Li, P. W., Mural, R. J., Sutton, G. G., ... Zhu, X. (2001). The sequence of the human genome. Science, 291, 1304-1351.

Verbeke, W., Bagozzi, R. P., \& van den Berg, W. E. (2014). The role of attachment styles in regulating the effects of dopamine on the behavior of salespersons. Frontiers in Human Neuroscience, 8(32), 1-13.

Verbeke, W., Bagozzi, R. P., van den Berg, W., Worm, L., \& Belschak, F. D. (2016). Sales presentation anxiety, cortisol levels self-reports, and gene-gene interactions. Journal of Marketing Behavior, 2, 225-252.

Verbeke, W. J. M. I., Belschak, F. D., Bagozzi, R. P., \& De Rijke, Y. B. (2015). Postgame testosterone levels of individuals in team-based status games are affected by genetic makeup, gender, and winning versus losing. Journal of Neuroscience, Psychology, and Economics, 8(3), 135-159.

Vul, E., Harris, C., Winkielman, P., \& Pashler, H. (2009). Puzzlingly high correlations in $\mathrm{fMRI}$ studies of emotion, personality, and social cognition. Perspectives on Psychological Science, 4(3), 274-290. 
Vytal, K., \& Hamann, S. (2010). Neuroimaging support for discrete neural correlates of basic emotions: A voxel-based meta-analysis. Journal of Cognitive Neuroscience, 22(12), 2864-2885.

Walter, H. (2012). Social cognitive neuroscience of empathy: Concepts, circuits, and genes. Emotion Review, 4(1), 9-17.

Wang, Y. J., \& Minor, M. S. (2008). Validity, reliability, and applicability of psychophysiological techniques in marketing research. Psychology \& Marketing, 25(2), 197-232.

Wicker, B., Keysers, C., Plailly, J., Royet, J.-P., Gallese, V., \& Rizzolatti, G. (2003). Both of us disgusted in my insula: The common neural basis of seeing and feeling disgust. Neuron, 40, 655-664.

Winkielman, P., Berridge, K. C., \& Wilbarger, J. L. (2005). Unconscious affective reactions to masked happy versus angry faces influence consumption behavior and judgments of value. Personality and Social Psychology Bulletin, 31(1), 121-135.

Wise, R. A., \& Rompre, P. P. (1989). Brain dopamine and reward. Annual Review of Psychology, 40, 191-225.

Wolfe, J. M., \& Horowitz, T. S. (2004). What attributes guide the deployment of visual attention and how do they do it? Nature Reviews Neuroscience, 5(6), 1-7.

Woodward, J. (2016). Causation and manipulability. In E. N. Zalta (Ed.), The Stanford encyclopedia of philosophy (Winter 2016 Edition). https://plato. stanford.edu/entries/causation-mani/
Xie, C., Bagozzi, R. P., \& Grønhaug, K. (2015). The role of moral emotions and individual differences in consumer responses to corporate green and non-green actions. Journal of the Academy of Marketing Science, 43(3), 333-356.

Yoon, C., Gonzalez, R., Bechara, A., Berns, G. S., Dagher, A. A., Dubé, L., ... Spence, C. (2012). Decision neuroscience and consumer decision making. Marketing Letters, 23(2), 473-485.

Yoon, C., Gutchess, A. H., Feinberg, F., \& Polk, T. A. (2006). A functional magnetic resonance imaging study of neural dissociations between brand and person judgments. Journal of Consumer Research, 33(1), 31-40.

van Zoest, W., Donk, M., \& Theeuwes, J. (2004). The role of stimulusdriven and goal-driven control in saccadic visual selection. Journal of Experimental Psychology: Human Perception and Performance, 30(4), 746-759.

How to cite this article: Shaw SD, Bagozzi RP. The neuropsychology of consumer behavior and marketing. Consum Psychol Rev. 2018;1:22-40. https://doi.org/10.1002/arcp.1006 